\title{
Optochemogenetic Stimulation of Transplanted iPS-NPCs Enhances Neuronal Repair and Functional Recovery after Ischemic Stroke
}

\author{
Shan Ping Yu, ${ }^{1,5}$ Jack K. Tung, ${ }^{3 *}$ ○Zheng Z. Wei, ${ }^{1,5 *}$ Dongdong Chen, ${ }^{1 * ~}$-Ken Berglund, ${ }^{3,5}$ Weiwei Zhong, ${ }^{1,5}$ \\ James Y. Zhang, ${ }^{1}$ Xiaohuan Gu, ${ }^{1,5}$ Mingke Song, ${ }^{1}$ - Robert E. Gross, ${ }^{3}$ Shinn Z. Lin, ${ }^{4}$ and Ling Wei ${ }^{1,2}$ \\ Departments of ${ }^{1}$ Anesthesiology, ${ }^{2}$ Neurology, ${ }^{3}$ Neurosurgery, Emory University School of Medicine, Atlanta, Georgia 30322, ${ }^{4}$ Department of Neurosurgery, \\ Tzu Chi Hospital, Tzu Chi University, Buddhist Tzu Chi Bioinnovation Center, Tzu Chi Foundation, Hualien, Taiwan 970, and ${ }^{5}$ Center for Visual and \\ Neurocognitive Rehabilitation, Atlanta Veterans Affairs Medical Center, Decatur, Georgia 30033
}

Cell transplantation therapy provides a regenerative strategy for neural repair. We tested the hypothesis that selective excitation of transplanted induced pluripotent stem cell-derived neural progenitor cells (iPS-NPCs) could recapitulate an activity-enriched microenvironment that confers regenerative benefits for the treatment of stroke. Mouse iPS-NPCs were transduced with a novel optochemogenetics fusion protein, luminopsin 3 (LM03), which consisted of a bioluminescent luciferase, Gaussia luciferase, and an opsin, Volvox Channelrhodopsin 1. These LM03-iPS-NPCs can be activated by either photostimulation using light or by the luciferase substrate coelenterazine (CTZ). In vitro stimulations of LM03-iPS-NPCs increased expression of synapsin-1, postsynaptic density 95 , brain derived neurotrophic factor (BDNF), and stromal cell-derived factor 1 and promoted neurite outgrowth. After transplantation into the ischemic cortex of mice, LM03-iPS-NPCs differentiated into mature neurons. Synapse formation between implanted and host neurons was identified using immunogold electron microscopy and patch-clamp recordings. Stimulation of transplanted cells with daily intranasal administration of CTZ enhanced axonal myelination, synaptic transmission, improved thalamocortical connectivity, and functional recovery. Patch-clamp and multielectrode array recordings in brain slices showed that CTZ or light stimulation facilitated synaptic transmission and induced neuroplasticity mimicking the LTP of EPSPs. Stroke mice received the combined LM03-iPS-NPC/CTZ treatment, but not cell or CTZ alone, showed enhanced neural network connections in the peri-infarct region, promoted optimal functional recoveries after stroke in male and female, young and aged mice. Thus, excitation of transplanted cells via the noninvasive optochemogenetics treatment provides a novel integrative cell therapy with comprehensive regenerative benefits after stroke.

Key words: functional recovery; iPS cells; neuronal repair; optochemogenetics; optogenetics; stroke

Significance Statement

Neural network reconnection is critical for repairing damaged brain. Strategies that promote this repair are expected to improve functional outcomes. This study pioneers the generation and application of an optochemogenetics approach in stem cell transplantation therapy after stroke for optimal neural repair and functional recovery. Using induced pluripotent stem cell-derived neural progenitor cells (iPS-NPCs) expressing the novel optochemogenetic probe luminopsin (LM03), and intranasally delivered luciferase substrate coelenterazine, we show enhanced regenerative properties of LMO3-iPS-NPCs in vitro and after transplantation into the ischemic brain of different genders and ages. The noninvasive repeated coelenterazine stimulation of transplanted cells is feasible for clinical applications. The synergetic effects of the combinatorial cell therapy may have significant impacts on regenerative approach for treatments of CNS injuries.

\section{Introduction}

Stroke is a leading cause of human death and long-term disability. While clinical trials have failed to recapitulate therapeutic benefits of neuroprotective treatments, regenerative treatments, such as cell transplantation, have provided a promising strategy for tissue repair and functional recovery after brain injuries (L. 
Wei et al., 2005; Hicks et al., 2009; N. Wei et al., 2013; Trounson and McDonald, 2015). Induced pluripotent stem (iPS) cells are particularly amenable for treating neurological diseases given their accessibility, differentiation potency, and clinical relevance. Transplantation of iPS-derived neural progenitor cells (iPSNPCs) after stroke in animal models shows potentials of cell replacement, increased trophic support, and functional improvements (Mohamad et al., 2013; Chau et al., 2014). Nevertheless, stem cell-based therapy is still nascent with ambiguous goals regarding their clinical efficacy and therapeutic mechanisms. Neuronal differentiation of transplanted cells and integration into the existing neural circuitry are key steps for effectual neuronal repair. Meanwhile, trophic support, such as increased BDNF, can augment functional recovery after injury (Kurozumi et al., 2005; van Velthoven et al., 2013). Strategies that enact these regenerative mechanisms should significantly improve therapeutic benefits of cell-based therapies.

Appropriate neuronal activity is essential for neuronal differentiation/maturation and cell survival; it is also critical for synaptic plasticity and specific functions (Zhang and Poo, 2001; Murphy and Corbett, 2009; Duan et al., 2017). Like immature neurons in the developing brain, the fate and functional phenotype of iPS-NPCs in the adult brain depend on the microenvironment in the transplantation site. Electrical activity and resultant cellular signaling act as critical cues for the differentiation of NPCs (Bergey et al., 1981; Zhang and Poo, 2001). Excitation of cultured primary and stem cell-derived neurons promotes neuronal morphogenesis (Wan et al., 2010; Kobelt et al., 2014). Increased neuronal activity elicits activity-dependent release of regenerative neurotrophins (Kolarow et al., 2007; Matsuda et al., 2009; Park and Poo, 2013). We hypothesized that selective stimulation of transplanted cells could create an enriched microenvironment and activity-dependent neuroplasticity in the poststroke brain for optimal neural network repair and functional recovery after stroke.

Optogenetics has transformed from an interrogative tool to a therapeutic means for regulating neuronal activity and restoring neural circuits in models of neurological diseases (Paz et al., 2013; Cheng et al., 2014; Cunningham et al., 2014; Steinbeck et al., 2016). The expression of light sensitive excitatory and inhibitory channels provides cell type-specific regulations with high spatial and temporal precision. In a mouse model of stroke, repeated optogenetic stimulation of the endogenous neurons in the motor cortex increased neurotrophin levels, resulting in improved functional recovery (Cheng et al., 2014). Optogenetic stimulation of neural grafts after stroke showed downregulation of inflammatory response and improved motor activity (Daadi et al., 2016). Whether the optogenetics approach incorporated in a cell transplantation therapy could improve host-graft connectivity, neural network repair, and other benefits after stroke has not been specifically tested.

This work was supported by National Institutes of Health Grants NS085568 to L.W., S.P.Y., and R.E.G., NS091585 to L.W., NS079268 to R.E.G., NS079757 to R.E.G., NS086433 to J.K.T., VA Merit Award RX000666, RX001473 to S.P.Y., National Science Foundation CBET-1512826 to K.B. and R.E.G., American Heart Association Predoctoral Fellowship PRE31230001 to J.Y.Z., and Postdoctoral Fellowships POST12080252 to M.S. and POST25710112/CDA34110317 to Z.Z.W. The Viral Vector Core of Emory Neuroscience National Institute of Neurological Disorders and Stroke Core Facilities was supported by National Institutes of Health Grant P30NS055077. We thank Dr. Michael Jiang, Dr. Myles R. McCrary, and Dupe Loye for help in proofreading and editing the manuscript; and Samuel I. Kim for help in CTZ administration and double-blind data analysis in behavioral tests.

The authors declare no competing financial interests.

*J.K.T., Z.Z.W., and D.C. contributed equally to this work.

Correspondence should be addressed to Ling Wei at Iwei7@emory.edu.

https://doi.org/10.1523/JNEUROSCI.2010-18.2019

Copyright $\odot 2019$ the authors
In the contest of clinical translation, optogenetics face a noteworthy restriction: the invasive implantation of an optical fiber. Moreover, light scatters within brain tissues, such that it is reduced to nearly negligible intensity within $\sim 200 \mu \mathrm{m}$ from the tip of the fiber (Yona et al., 2016), resulting in limited spatial control of cells in the human brain. Here, we exploited a fusion protein, luminopsin 3 (LMO3), which comprises a modified variant of the bioluminescent protein, Gaussia luciferase (sbGLuc), tethered to an excitatory light-sensitive channel, Volvox Channelrhodopsin 1 (VChR1). iPS-NPCs expressing LMO3 can be excited by both physical and biological light sources (hereafter referred to as optochemogenetics), providing a novel noninvasive combinatorial stimulation method in a cell transplantation therapy. The combination therapy was tested in vitro and after a focal ischemic stroke in mice of different genders and ages, the optochemogenetics treatment show enhanced regenerative benefits and offer a greater potential for clinical applications.

\section{Materials and Methods}

\section{iPS cell cultures and neuronal differentiation}

Mouse WP5 iPS cells were purchased from Stemgent. Undifferentiated iPS cells were cultured in $0.1 \%$ gelatin-coated T25 flasks in stem cell culture media consisting of DMEM (Corning), 10\% FBS (Invitrogen), 10\% NCS (Sigma-Aldrich), 2 mm glutamine (Stem Cell Technologies), $0.1 \mathrm{~mm}$ nonessential amino acids (Stem Cell Technologies), $55 \mu \mathrm{M}$ 2-mercaptoethanol (Sigma-Aldrich), $2000 \mathrm{U} / \mathrm{ml}$ LIF (Miltenyi Biotec), and $100 \mathrm{U} / \mathrm{ml}$ penicillin/streptomycin (Corning). For neuronal differentiation, iPS cells were differentiated in suspension culture with the " $4-1$ $4+$ " protocol ( $4 \mathrm{~d}$ without and then $4 \mathrm{~d}$ with $1 \mu \mathrm{M}$ all-trans retinoic acid [RA] in LIF-free medium) under rotary condition as previously described (Bain et al., 1995). Briefly, cells were dissociated from the growth flasks by trypsinization with $0.25 \%$ trypsin-EDTA (Invitrogen) for 2 $\mathrm{min}$. Then cells were seeded onto standard $10 \mathrm{~cm}$ bacterial Petri dishes in stem cell culture media lacking LIF and $\beta$-mercaptoethanol. Within the first day, the cells formed embryoid bodies in suspension culture. In the last $4 \mathrm{~d}, 500 \mathrm{~nm}$ of all-trans RA(Sigma-Aldrich) was added to the media. After $4-/ 4+$ culture, the iPS cell-differentiated iPS-NPCs were ready to be dissociated and harvested for transplantation or in vitro terminal differentiation on poly-D-lysine/laminin-coated dishes in modified SATO media (Bottenstein and Sato, 1979). For electrophysiology recordings, iPS-NPCs were plated on a layer of astrocytes for longer terminal differentiation up to $12 \mathrm{~d}$ after the " $4-/ 4+$ " neural induction.

\section{Optogenetics gene modification of mouse iPS cells and}

\section{virus infections}

Luminopsins are fusion proteins of luciferase and opsin that can be activated by either extrinsic physical light (i.e., laser and LED) or by intrinsic biological light with chemical substrate. To enable iPS-NPCs to be depolarized by both blue light and intrinsic luminescence, we created the episomal backbone carrying an LMO3 construct ( pLenti-CAG-sbGLucVChR1-EYFP-IRES-PuroR). The luciferase sbGLuc in the LMO3 construct allows for its activation by the luciferase substrate coelenterazine (CTZ), which in turn activates VChR1 channels expressed in the cell membrane, resulting in membrane depolarization.

To express with an EYFP tag using a single plasmid, pEGIP (a gift from Linzhao Cheng; Addgene, plasmid \#26777) was used. The GFP-IRESPuro sequence was modified by restriction enzyme digestion and ligation to replace the GFP with the LMO3-EYFP sequence. This optogenetics and chemogenetics channel was amplified from plasmids in our previous reports (Berglund et al., 2013, 2016b). LMO3-EYFP lentivirus was added into the iPS cells seeded at $5 \times 10^{5}$ cells per well in vitro. At $4 \mathrm{~d}$ after infection, cells were subjected to puromycin selection at $15 \mu \mathrm{g} / \mu \mathrm{l}$. Positive clones were selected, and then the highest EYFP-expression colonies were expanded to form stable LMO3-iPS cells that coexpressed the EYFP tag with several pluripotent stem cell markers SSEA-1, Oct 3/4, or Nanog (Fig. 1A). The stable cell line (LMO3-iPS) was maintained in culture medium containing puromycin $(0.5 \mu \mathrm{g} / \mathrm{ml})$. 
A

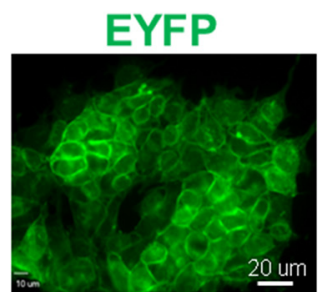

SSEA-1

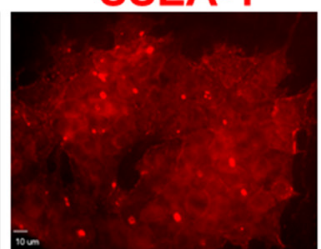

Hoechst

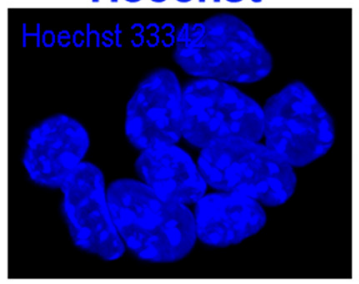

Oct $3 / 4$

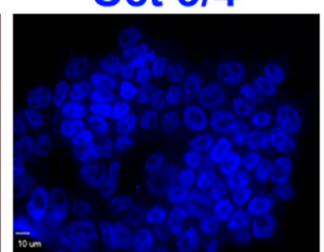

Nanog

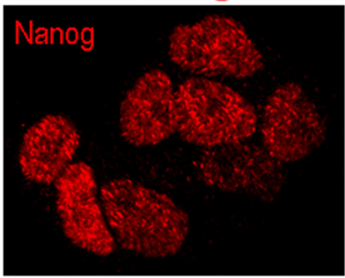

Hoechst

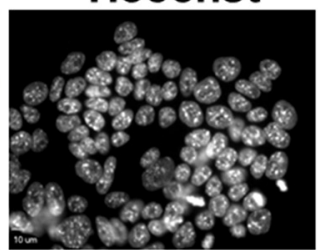

Merge

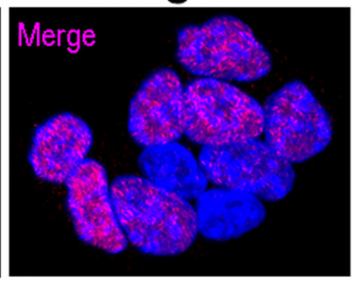

B

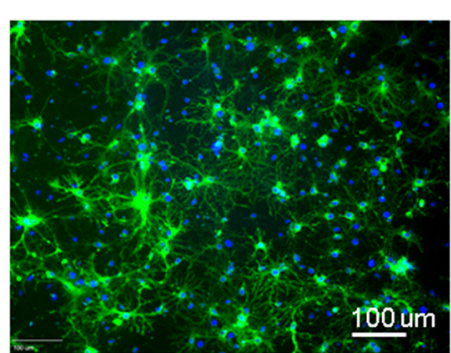

C

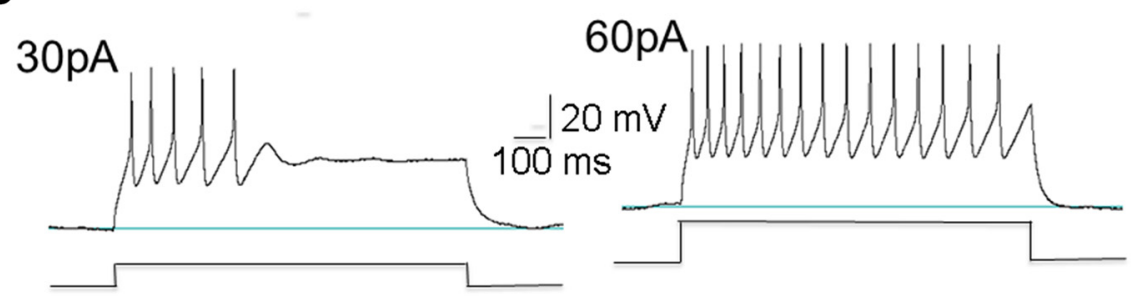

Laser light

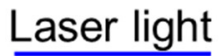

D
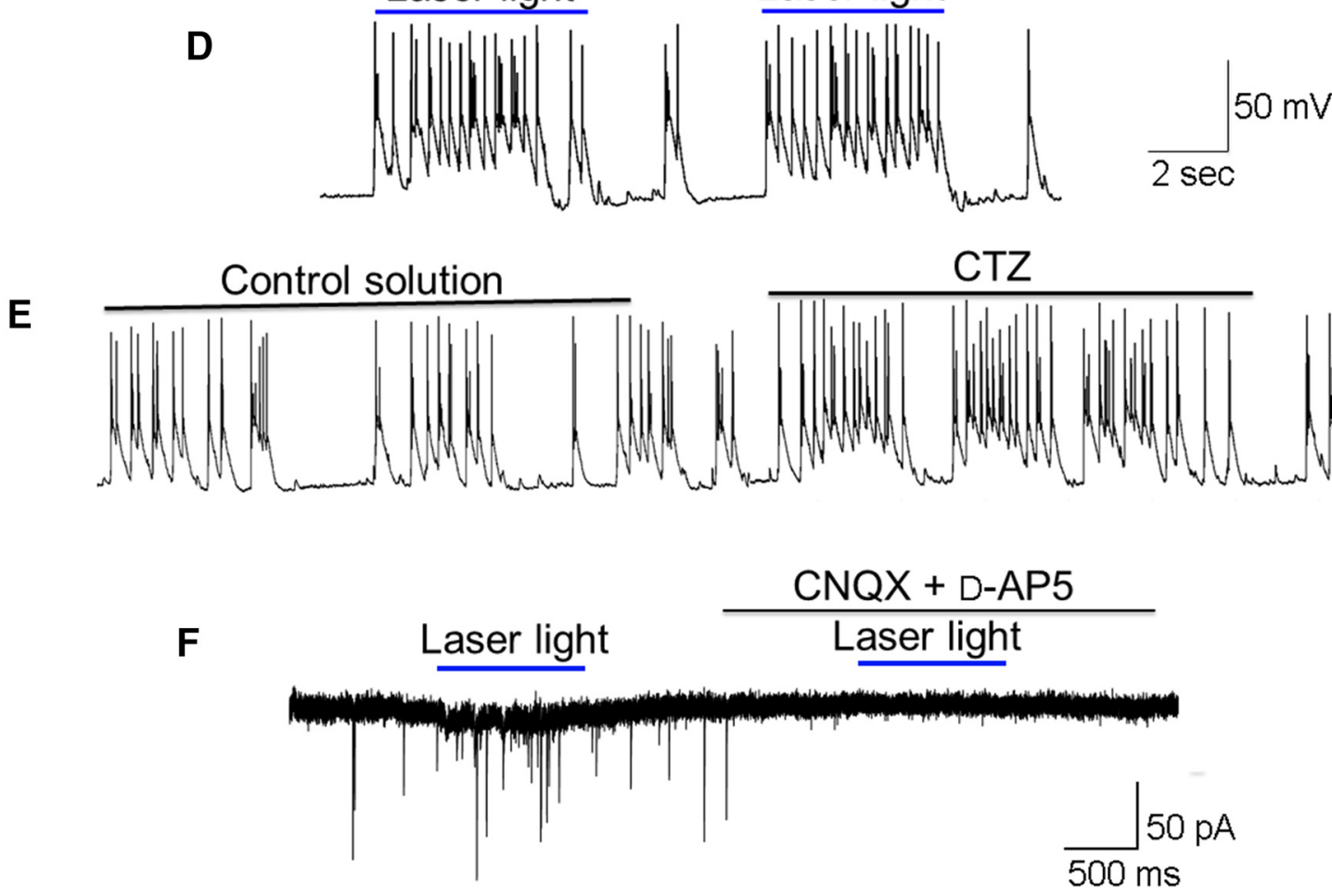

Figure 1. Expression of LM03 in iPS-NPCs and functional activities of derived neurons. $A$, A stable iPS cell line expressing luciferase (LM03-iPS cell line) was generated by transduction of the modified LM03 construct (pLenti-CAG-sbGLuc-VChR1-EYFP-IRES-PuroR) and subsequent puromycin selection. Immunocytochemistry showed that LM03-iPS cells express pluripotent stem cell markers SEEA-1, 0ct 3/4, and Nanog, which colabeled with fluorescent protein EYFP tagged to the LM03 construct. $\boldsymbol{B}$, Differentiated iPS-NPCs showed neuronal morphology of neurites and axons. Green is from EYFP fluorescence in transfected cells. $C$, In whole-cell recording of current clamp on LM03-iPS-NPC-derived neuron-like cells, current injection of 30 and 60 pA induced membrane depolarization and repetitive action potentials. $\boldsymbol{D}$, Demonstration of blue light induced trains of action potential in LM03-iPS-NPC-derived neurons. $E$, Bath application of CTZ (6 $\mu \mathrm{M}$ ) significantly increased the firing frequency in LM03-expressing cortical neurons compared with vehicle control. The firing rate in the cell increased from $2.6 \pm 0.9 \mathrm{~Hz}$ to $4.3 \pm 0.5 \mathrm{~Hz}$ ( $p<0.05, t$ test, $n=5$ each). $F$, In voltage-clamp recording, blue laser light $(473 \mathrm{~nm}, 33.6 \mathrm{~mW})$ stimuli evoked inward currents resembling EPSCs in LM03-iPS-NPC-derived neurons. Light stimulation effect in the same cell was completely blocked by the AMPA and NMDA receptor antagonists CNQX and AP5. Different cells were recorded in $\mathbf{D}-\boldsymbol{F}$. 
The point mutation, D248A, as well as a new AfeI restriction site, was introduced into the VChR1 moiety of LMO3 using a commercial mutagenesis kit following the manufacturer's instructions and their online primer design software (QuikChange XL; Agilent Technologies). First, the LMO3 cassette in the pcDNA3.1/CAG vector (Berglund et al., 2016a) was moved into the pGP/CMV vector (Addgene, plasmid \#40753, a gift from Douglas Kim) using the unique NheI/BsrGI restriction sites, and then site-directed mutagenesis was performed. The correct sequence was confirmed by an AfeI restriction enzyme analysis as well as DNA sequencing. The mutated LMO3/D248A cassette was put back to the original pcDNA3.1/CAG vector using the same restriction sites and transfection-grade plasmids were prepared using a commercial kit (PureLink Midiprep Kit; Invitrogen). For electrophysiological recordings and a plate reader assay in vitro, human embryonic kidney 293 cells were transiently transfected via lipofection following the conventional method (Berglund et al., 2016b) and manufacturer's instructions (Lipofectamine 2000; Invitrogen). For in vivo experiments, a stably transfected iPS cell line was established by lipofection followed by antibiotic selection using the neomycin resistance gene in the pcDNA3.1/CAG vector. In another control experiment, iPS cells were transduced with a recombinant adeno-associated viral (AAV) vectors pseudotyped with AAV2/9 carrying the channelrhodopsin 2 (ChR2) gene from the pAAV/ CaMKII $\alpha$-hChR2/H134R-mCherry-WPRE plasmid in Emory Viral Core. ChR2 alone lacked luciferase, serving as a negative control for CTZ administration.

For the expression of LMO3 in naive animals, AAV vectors carrying the LMO3 gene under control of the human synapsin-1 promoter were similarly produced and injected into the sensorimotor/barrel cortex $\left(-2.54 \mathrm{~mm}\right.$ AP, $3.5 \mathrm{~mm} \mathrm{ML}, 0.4 \mathrm{~mm} \mathrm{DV}, 30^{\circ}$ angle) using a Hamilton syringe on a stereotaxic platform ( $1 \mu \mathrm{l}$ or $\sim 1 \times 10^{7}$ viral genomes). Three to 4 weeks after infection, animals were subjected to in vivo tests and killed by overdose of isoflurane and decapitated for brain dissection followed by tissue and cellular examinations.

\section{Isolation of total RNA and RT-PCR}

Total RNA from LMO3-iPS-derived neurons was isolated according to the manufacturer's instructions (Invitrogen). In brief, the RNA samples $(1 \mu \mathrm{g})$ were reverse transcribed in $20 \mu \mathrm{l}$ of a reaction mixture containing $2 \times \mathrm{RT}$ buffer and $20 \times \mathrm{RT}$ enzyme mix at $37^{\circ} \mathrm{C}$ for $60 \mathrm{~min}$. The samples were then incubated at $95^{\circ} \mathrm{C}$ for $5 \mathrm{~min}$ and transferred to $4^{\circ} \mathrm{C}$. RT product $(1 \mu \mathrm{l})$ was subjected to PCR amplification with $10 \mathrm{pmol}$ primer, $10 \times$ standard Taq reaction buffer, $10 \mathrm{~mm}$ dNTP, and 0.625 unit Taq polymerase in $25 \mu \mathrm{l}$ PCR buffer (New England Biolabs). PCR primers were used as follows $\left(5^{\prime}-3^{\prime}\right)$ : stromal cell-derived factor $1 \alpha$ (SDF-1 $\left.\alpha\right)$ : GCATAAAGACACTCCGCCAT (forward) and TGAGGAGAATGGGGATGAAG (reverse); synapsin-1: CAGCACAACATACCCTATGC (forward) and GGTCTTCCAGTTACCCGACA (reverse); postsynaptic density 95 (PSD95): GGCACCGACTACCCCACAG (forward) and AACACCATTGACCGACAGGA (reverse); 18s: GACTCAACACGGGAAACCTC (forward) and ATGCCAGAGTCTCGTTCGTT (reverse). PCR mixtures were heated to $95^{\circ} \mathrm{C}$ for $10 \mathrm{~min}$ and cycled $30-37$ times for each primer; cycles consisted of $95^{\circ} \mathrm{C}$ for $15 \mathrm{~s}, 60^{\circ} \mathrm{C}$ for $1 \mathrm{~min}$, and $72^{\circ} \mathrm{C}$ for $30 \mathrm{~s}$. After additional incubation at $72^{\circ} \mathrm{C}$ for $10 \mathrm{~min}$, the PCR samples were transferred to $4^{\circ} \mathrm{C}$. PCR products were subjected to electrophoresis in $2 \%$ agarose gel with ethidium bromide. Relative intensity of a PCR band was analyzed using InGenius3 manual gel documentation systems (Syngene).

\section{Immunocytochemical and immunohistochemical staining}

Cultured cells were fixed with 4\% PFA in PBS and postfixed with 2:1 mixture of enthanol:acetic acid for $5 \mathrm{~min}$, then permeabilized with $0.2 \%$ Triton X-100 and blocked with $1 \%$ fish gelatin. Cells were incubated overnight at $4^{\circ} \mathrm{C}$ with primary antibodies against GFP (1:200; Novus Biologicals; used to stain for the EYFP tag in LMO3), NeuN (1:400; Millipore), $\beta$-III tubulin (Tuj-1, 1:400; Covance), synapsin-1 (1:400; Millipore), neurofilament (NF, 1:400; Millipore), CaMKII (1:400; Millipore), FoxG-1 (1:200; Abcam), SEEA-1 (1:200; Abcam), Nanog (1:100; Santa Cruz Biotechnology), Oct 3/4 (1:100; Santa Cruz Biotechnology), vesicular glutamate transporter 1 (VGLUT1, 1:200; Abcam), and vesicular glutamate transporter 2 (VGLUT2, 1:200; Abcam). For the secondary antibodies, either AlexaFluor-488 (1:100; Invitrogen) or Cy-3 (1:400; Jackson ImmunoResearch Laboratories) conjugated antibody against the respective IgG was used. DAPI within the DAPI-Vectashield (Vector Labs) was used to stain cell nuclei.

For immunohistochemistry, animals were subjected to cardiac perfusion with PBS followed by 4\% PFA in PBS. Fixed brains were sectioned at $10-\mu \mathrm{m}$-thick coronal sections with a cryostat (Leica Microsystems). Brain sections were postfixed in 10\% buffered formalin for $10 \mathrm{~min}$ followed by 2:1 mixture of enthanol:acetic acid for $5 \mathrm{~min}$. Standard staining protocols were then followed for GFP (1:200; Novus Biologicals), NeuN (1:400; Millipore), synapsin-1 (1:200; Millipore), glucose transporter-1 (Glut-1, 1:400; Millipore), and myelin basic protein (MBP, 1:400; Millipore). The GFP antibody was used to stain for the EYFP tag in LMO3. For BrdU (1:400; AbD Serotec) staining, slides were fixed by cold methanol followed by hydrochloric acid $(\mathrm{HCl})$ treatment for $1 \mathrm{~h}$. Then standard staining procedures were followed. Pictures were taken by using a fluorescence microscope (BX61; Olympus) or a laser scanning confocal microscope (Carl Zeiss) along the length of the penumbra region defined morphologically as the region just outside the stroke core. The colabeling was confirmed using the confocal microscope (FV1000, Olympus). For systematic random sampling in design-based stereological cell counting, six coronal brain sections per mouse were selected, spaced $90 \mu \mathrm{m}$ apart across the same ROI in each animal. For multistage random sampling, six fields per brain section were randomly chosen in the peri-infarct/penumbra region of the brain. The fluorescence density was measured using National Institutes of Health ImageJ software.

\section{Western blot analysis}

Proteins were extracted from iPS-NPC-derived neurons using the lysis buffer containing the protease inhibitor mixture containing AEBSF, aprotinin, bestatin, E-64, leupeptin, and pepstatin A (1:100; SigmaAldrich). Protein concentrations were quantified by the BCA assay. Protein $(30 \mu \mathrm{g})$ from each sample were loaded into a gradient gel and run at constant current until protein markers had adequately separated. They were transferred onto PVDF membranes that were then probed by using standard protocols. Primary antibodies, synapsin-1 (1:1000; Cell Signaling Technology), PSD95 (1:500; Cell Signaling Technology), BDNF (1: 500; Santa Cruz Biotechnology), and mouse $\beta$-actin antibody (1:6000; Sigma-Aldrich) were applied overnight at $4^{\circ} \mathrm{C}$. Alkaline phosphataseconjugated secondary antibodies were applied for $1-2 \mathrm{~h}$ at room temperature. Alkaline phosphatase-conjugated antibodies were developed by using NBT-BCIP solution. The intensity of each band was measured and subtracted by the background using National Institutes of Health ImageJ software. The expression ratio of each target protein was then normalized against $\beta$-actin.

\section{Calcium imaging in cultured iPS-NPCs and neurons}

iPS-NPCs were loaded with the fluorescent $\mathrm{Ca}^{2+}$ dye, fura-2, in a membrane-permeable (AM) form (Invitrogen; $5 \mu \mathrm{M}$ in $100 \mu \mathrm{l}$ HEPESbuffered solution), inside a $\mathrm{CO}_{2}$ incubator. fura-2 fluorescence was alternately excited at 340 and $380 \mathrm{~nm}$ light, and emission ratio to the $340 / 380 \mathrm{~nm}$ excitation was determined (BX51; Olympus).

Lactate dehydrogenase $(\mathrm{LDH})$ release of cell death assay

The potential effect of optogenetic/chemogenetic stimulation on cell death was measured using the LDH released assay. LDH release from cells was detected using the Cytotoxicity Detection Kit (Roche Diagnostics) and a fluorometric plate reader (FL-600; Bio-Tek Instruments) following the manufacturer's instruction manual.

\section{Immunoelectron microscopy of brain sections}

One to 1.5 months after transplantation, animals were killed and perfused transcardially with 4\% PFA in $0.1 \mathrm{M} \mathrm{PB}, \mathrm{pH}$ 7.2-7.4. Immunoelectron microscopy was performed at Emory Electron Microscopy Core according to previous published method for immunogold-silver labeling at ultrastructural level (Yi et al., 2001). Perfusion fixed brains were further fixed with 4\% PFA in PB overnight and then sectioned coronally at $50 \mu \mathrm{m}$ using a cryostat vibratome (Ultrapro 5000). The sections were washed thoroughly with $\mathrm{PB}$ and then placed in $\mathrm{PB}$ containing $0.1 \%$ sodium borohydride to inactivate residual aldehyde groups in the tissue 
sections. Sections were washed with PB several times until the solution was devoid of bubbles. To improve antibody penetration, the sections were treated with $\mathrm{PB}$ containing $0.05 \%$ Triton X-100 for $20 \mathrm{~min}$ before incubating in a blocking solution containing $5 \%$ BSA, and $0.1 \%$ cold water fish skin gelatin. After blocking, sections were rinsed twice with PBS containing $0.2 \%$ acetylated BSA (PBS/BSA-c; pH 7.4) and then incubated overnight at $4^{\circ} \mathrm{C}$ in a mixture of goat anti-GFP $(5 \mu \mathrm{g} / \mathrm{ml})$ and mouse anti-tubulin (1:100), or goat anti-GFP and mouse anti-neuronal nuclei (both at $5 \mu \mathrm{g} / \mathrm{ml}$ ) primary antibodies diluted in PBS/BSA-c. The neuronal GFP immunolabeling helped the identification of neuronal cells derived from transplanted cells in electron microscopy (EM) images. After washes with PBS/BSA-c, sections were incubated overnight at $4^{\circ} \mathrm{C}$ in the secondary antibody conjugate, ultrasmall gold-conjugated donkey anti-goat IgG diluted 1:100 with PBS/BSA-c. To remove unbound secondary antibody, sections were washed thoroughly with PBS/ $\mathrm{BSA}-\mathrm{c}$ and then with $\mathrm{PB}$.

Following PB washes, sections were washed with enhancement conditioning solution and then placed in R-Gent SE-EM silver enhancement solution for $90 \mathrm{~min}$. Silver enhancement was terminated using $0.03 \mathrm{M}$ sodium thiosulfate in enhancement conditioning solution. After the first silver enhancement, sections were washed with $\mathrm{PB}$. Sections were incubated overnight at $4^{\circ} \mathrm{C}$ again with the secondary antibody conjugate, ultrasmall gold-conjugated donkey anti-mouse IgG diluted 1:100 in PBS/ BSAc. Sections were washed with PBS/BSAc and then PB. Before the second silver enhancement of $60 \mathrm{~min}$, sections were fixed with $2.5 \%$ glutaraldehyde in PB. All immunoincubations were done with gentle agitation $4^{\circ} \mathrm{C}$, and all immunoEM reagents were purchased from Electron Microscopy Sciences.

Following fixation, sections were washed with $\mathrm{PB}$, fixed with $0.5 \%$ osmium tetroxide for $15 \mathrm{~min}$, dehydrated, and flat-embedded in Eponate 12 resin (Ted Pella) between two sheets of Aclar film. After resin polymerization, small pieces of flat-embedded sections were dissected from the cortex, mounted on plastic stubs, and sectioned en face at $80 \mathrm{~nm}$ with an ultramicrotome (Leica Microsystems, UC6rt). Sections were then stained with $5 \%$ uranyl acetate and 2\% lead citrate. Imaging was done on a transmission electron microscope (JEM-1400, JEOL) that is equipped with a 4 million-pixel charge-coupled device camera (US1000, Gatan).

\section{In vitro neurite/axon morphology and outgrowth analysis}

An axon isolation device (Axon investigation system, AXIS, Millipore) was used to measure the process length and distribution of iPS-NPCderived neurons. The AXIS device has a two-chamber system, which was separated by a set of microgrooves, allowing for the separation of cell body and axons/dendrites and allow only for axon/dendrite crossing. The measurement followed the manufacturer's instruction. Briefly, after the " $4-/ 4+$ " RA neural differentiation, LMO3-expressing iPS-NPCs were dissociated and plated into one of the culture chambers in SATO medium, and the other culture chamber was filled with SATO medium without cells. The cells in the photostimulation group received blue light stimuli as described below for 5 consecutive days starting from $1 \mathrm{~d}$ after plating. Cells in the CTZ group received CTZ treatment (1.5 $\mu \mathrm{M}$ bath application for $15 \mathrm{~min}, 3$ times a day for $5 \mathrm{~d}$ ). Cells in the control group received the medium change without CTZ. On day 6 after plating, the cells were fixed and stained for the neurite marker Tuj-1. The Tuj-1positive neurites were imaged using confocal microscopy. The distance and diameter of processes extended from the microgrooves were measured using National Institutes of Health ImageJ. The diameter of each process was measured at five random areas, and the average diameter was presented in this report. The number and length of processes that crossed the microgroove barrier into the axonal chamber were counted and compared among groups.

The Sholl analysis of major process sprouting was performed using ImageJ software (National Institutes of Health). Briefly, processes $>20$ $\mu \mathrm{m}$ originating from the branch point were counted. Concentric circles with $15 \mu \mathrm{m}$ differences in diameter were drawn in the end of microgrooves, and the number of processes crossing each circle was manually counted. The investigators were blind to the treatment groups.

\section{Experimental design}

Light and CTZ stimulation of $i P S-N P C s$ in vitro. In vitro experiments were performed on LMO3-iPS-NPCs. The total number of iPS cell culture dishes tested was 51 cultures dishes/plates from different batches. Starting $1 \mathrm{~d}$ after the " $4-/ 4+$ " differentiation and plating, cells were subjected to blue light stimulation $(473 \mathrm{~nm}, 36 \mathrm{~mW}$ for $5 \mathrm{~ms}$ at $10 \mathrm{~Hz}$ for $12 \mathrm{~s}$ followed by a $48 \mathrm{~s}$ off period repeated 15 times; 3 times a day with a minimum of $2 \mathrm{~h}$ interval) for 5-6 consecutive days. The optical fiber of $200 \mu \mathrm{m}$ core diameter, connected to a laser source (BL473T3-100FC, SLOC), was placed $5 \mathrm{~mm}$ below the culture dish. The peak irradiance at the level of the specimen (i.e., at the bottom of culture dish) was determined by an optical power meter console (ThorLabs) to be $\sim 1$ $\mathrm{mW} / \mathrm{mm}^{2}$.

The same laser light source or wide-field illumination through a green filter cube in an epi-fluorescent unit in a microscope (440-520 nm; 2.1 $\mathrm{mW} / \mathrm{mm}^{2}$ ) was used for all in vitro light stimulation experiments. Cells in the CTZ group received CTZ exposure $(1.5 \mu \mathrm{M})$ for $15 \mathrm{~min}, 3$ times a day with a minimum of $2 \mathrm{~h}$ interval for 5-6 consecutive days $(n=12$ cultures). Cells in the control group received medium changes that contained vehicle for CTZ following the same schedule ( $n=9$ cultures).

Focal ischemic stroke model of the mouse. A total of 442 adult male C57BL/6 mice (2- to 3-month-old; body weight $=24.1 \pm 0.7 \mathrm{~g}$ for male, $22.3 \pm 0.8 \mathrm{~g}$ for female) and 80 aged mice (18- to 20-month-old, $30.7 \pm$ 2.1 for male, $27.1 \pm 2.0$ for female) (Charles River Laboratories) were used in stroke experiments. The animal number in each group was determined based on the mortality of the distal middle cerebral artery ischemic surgery ( $\sim 5 \%$ for young adult and $\sim 10 \%$ for aged animals), the variables in measurements and our previous data. Randomization was performed, and the sample size was further determined using power analysis (Power and Precision 4; Biostat).

Focal cerebral ischemia was induced and housed at Emory University Animal Facility in standard cages in $12 \mathrm{~h}$ light/ $12 \mathrm{~h}$ dark cycles. The ischemic stroke in the sensorimotor cortex was induced based on the barrel cortex stroke model, with modified artery occlusion procedures (L. Wei et al., 1995; Choi et al., 2012). Briefly, anesthesia was induced using 3.5\% isoflurane followed by the maintenance dose of $1.5 \%$ isoflurane. Both the tail and paws of the animal were pinch-tested for anesthetic depth. The right middle cerebral artery was permanently ligated using a 10-0 suture (Surgical Specialties), accompanied by bilateral common carotid artery ligations for $7 \mathrm{~min}$. This modified ischemic procedure is suitable and sufficient for the induction of focal ischemia in the mouse cortex, resulting in specific infarct formation in the right sensorimotor cortex. During surgery and recovery periods, body temperature was monitored and maintained at $37.0 \pm 0.5^{\circ} \mathrm{C}$ using a temperature control unit and heating pads. The focal ischemic surgery caused low mortality rate ( $\sim 5 \%$ of $3 \mathrm{~d}$ survival). All animal experiments and surgery procedures were approved by the Institutional Animal Care and Use Committee and met the National Institutes of Health standard.

Transplantation of iPS-NPCs into the postischemic brain. Cell transplantation was performed at $7 \mathrm{~d}$ after the focal ischemic stroke. Three experimental groups were stroke control, iPS-NPC transplantation with vehicle, and iPS-NPC transplantation stimulated with CTZ (at least 10 animals in each group; specific numbers are mentioned in figure legends of each experiment of different figures). Animals were randomly assigned to the groups. After the " $4-/ 4+$ " neural induction, $5 \times 10^{5}$ LMO3-iPS derived LMO3-iPS-NPCs were resuspended in $4 \mu \mathrm{l}$ SATO medium and transplanted to the core and peri-infarct regions using a Hamilton syringe with injections of $1 \mu \mathrm{l}$ each at 4 locations (site $1: \mathrm{AP}=$ 1.6, $\mathrm{L}=-4.0, \mathrm{~V}=-6.5$; site 2 : $\mathrm{AP}=0.6, \mathrm{~L}=-3.0, \mathrm{~V}=-5.5$; site 3 : $\mathrm{AP}=-0.6, \mathrm{~L}=-4.5, \mathrm{~V}=-7.0$; and site $4: \mathrm{AP}=-2.6, \mathrm{~L}=-6.5, \mathrm{~V}=$ $-4.5)$ in the peri-infarct cortex. A 2 min waiting period at the end of injection allowed the cells to settle before needle removal. Stroke control animals received vehicle injection ( $4 \mu \mathrm{l}$ of SATO medium). In some experiments, iPS-NPCs were prelabeled with Hoechst 33342 (1:10,000 $\mathrm{v} / \mathrm{v}$ ) for $1 \mathrm{~h}$, which facilitated tracking of these cells after transplantation. To enhance cell survival and regenerative property after transplantation, all iPS-NPCs were exposed to hypoxic preconditioning $\left(1 \% \mathrm{O}_{2}\right)$ for $8 \mathrm{~h}$ before transplantation (Theus et al., 2008; Yu et al., 2013). To label proliferating cells in the brain, animals received daily administration of 
BrdU (50 mg/kg; i.p.) starting the day of transplantation until the day of death.

Intranasal CTZ administration in vivo. For delivery of CTZ in vivo, we used the nasal route that allows reagents to bypass the blood-brain barrier and achieve brain targeted drug delivery (Hanson and Frey, 2008; Chen et al., 2015; Meredith et al., 2015). Intranasal administration of CTZ followed previous procedures at a dosage of $50 \mu \mathrm{g}$ per animal $(\sim 2$ $\mathrm{mg} / \mathrm{kg}$, dissolved in sterile saline) each time (Chen et al., 2015). Animals received two CTZ treatments per day for 2 weeks (at least 10 animals in each group; specific numbers are mentioned in figure legends of each experiment).

In vivo bioluminescence imaging. We performed the in vivo bioluminescence imaging using a chemiluminescence reader (LAS-3000; Fujifilm), which is equipped with a charge-coupled device camera for high-sensitivity detection of bioluminescent emission. For each experiment, the animals were anesthetized with the ketamine/xylazine mixture (ketamine $80-100 \mathrm{mg} / \mathrm{kg}$, xylazine $10-12.5 \mathrm{mg} / \mathrm{kg}$, i.p.) and given CTZ $(50 \mu \mathrm{g})$ intranasally followed by imaging ( $n=3$ animals). Using the chemiluminescence mode, the images were acquired as cumulative emission intensities every $4 \mathrm{~min}$ over the course of 60-90 min. The background-corrected luminescence intensity in an ROI was measured.

Electrophysiological recordings in cultured cells and brain slices. Wholecell patch-clamp recording in dissociated cells in cultures was performed using an inverted microscope (IX71; Olympus) equipped with an epifluorescent unit (Olympus), an electromechanical shutter (Uniblitz; Vincent), a mercury lamp (Olympus), and a scientific CMOS camera (OptiMOS; QImaging) on iPS cell-derived neurons 7-12 d after neural induction, which were growing on top of an astrocytes layer. Whole-cell recording was also done on acute brain slices of naive mice expressing LMO3 using an upright microscope (LABOPHOT; Nikon). The membrane currents or potentials were collected using an amplifier (EPC9; HEKA Elektronik) at room temperature $\left(\sim 22^{\circ} \mathrm{C}\right)$. The external solution contained $135 \mathrm{~mm} \mathrm{NaCl}, 5 \mathrm{~mm} \mathrm{KCl}, 2 \mathrm{~mm} \mathrm{MgCl}, 1 \mathrm{~mm} \mathrm{CaCl}_{2}, 10 \mathrm{~mm}$ HEPES, and $10 \mathrm{~mm}$ glucose, $\mathrm{pH}$ 7.4. The internal solution consisted of $120 \mathrm{~mm} \mathrm{KCl}, 2 \mathrm{~mm} \mathrm{MgCl}_{2}, 1 \mathrm{~mm} \mathrm{CaCl}, 2 \mathrm{~mm} \mathrm{Na}_{2} \mathrm{ATP}, 10 \mathrm{~mm}$ EGTA, and $10 \mathrm{~mm}$ HEPES, pH 7.2. Recording electrodes pulled from borosilicate glass pipettes (P-97; Sutter Instruments) had a tip resistance between 5 and $7 \mathrm{M} \Omega$ when filled with the internal solution. Series resistance was compensated by $75 \%-85 \%$. Linear leak and residual capacitance currents were subtracted online using a $\mathrm{P} / 6$ protocol. Action potentials were recorded under current-clamp mode using patch-clamp software (PatchMaster; HEKA Elektronik). Data were filtered at $3 \mathrm{kHz}$ and digitized at sampling rates of $20 \mathrm{kHz}$.

In brain slice patch-clamp recordings, the forebrain was dissected and immediately placed in sucrose-enriched cutting solution containing 220 mм sucrose, $1.9 \mathrm{~mm} \mathrm{KCl,} 6 \mathrm{~mm} \mathrm{MgCl}, 2.5 \mathrm{~mm} \mathrm{CaCl}_{2}, 1.2 \mathrm{~mm} \mathrm{NaH}_{2} \mathrm{PO}_{4}$, $33 \mathrm{~mm} \mathrm{NaHCO}_{3}$, and $10 \mathrm{~mm}$ D-glucose. The solution was ice-cold and bubbled with $95 \% \mathrm{O}_{2}$ balanced with $5 \% \mathrm{CO}_{2}, \mathrm{pH} 7.40$. Coronal brain sections (200 or $400 \mu \mathrm{m}$ thickness) containing the sensorimotor/barrel cortex were obtained using a vibratome sectioning device (1000 Plus; Vibratome) and then recovered for at least $60 \mathrm{~min}$ in the aCSF before recordings.

For poststroke recordings, whole-cell voltage clamp was performed on brain slices containing the ischemic core and peri-infarct regions. The pipette puller was used to pull the patch pipettes with the tip resistances of 3-5 $\mathrm{M} \Omega$. During recording, slices were maintained at $34^{\circ} \mathrm{C}$ and perfused with oxygenated aCSF containing $124 \mathrm{~mm} \mathrm{NaCl}, 3 \mathrm{~mm} \mathrm{KCl}, 2 \mathrm{~mm}$ $\mathrm{MgCl}_{2}, 2 \mathrm{~mm} \mathrm{CaCl}$, $1.3 \mathrm{~mm} \mathrm{NaH} \mathrm{PO}_{4}, 26 \mathrm{~mm} \mathrm{NaHCO}_{3}$, and10 mm D-glucose at a rate of $2 \mathrm{ml} / \mathrm{min}$. The pipette was filled with a solution containing $130 \mathrm{~mm}$ K-gluconate, $10 \mathrm{~mm} \mathrm{KCl}, 10 \mathrm{~mm}$ HEPES, $2 \mathrm{~mm} \mathrm{Mg-}$ ATP, 0.3 mm Na-GTP, and 0.4 mM EGTA, pH 7.3. Recorded signals were amplified with a patch-clamp amplifier (Axopatch 200B; Molecular Devices), digitized at $10 \mathrm{kHz}$, filtered at $1 \mathrm{kHz}$, and collected with data acquisition software (Clampex 8.2; Molecular Devices). Only the neurons with membrane potential more negative than $-40 \mathrm{mV}$ and action potential $>65 \mathrm{mV}$ were accepted for further experiments. EPSCs were recorded as inward currents at the holding potential of $-70 \mathrm{mV}$. The electrophysiological data were analyzed using commercial software (Mini Analysis 6.0.7; Synaptosoft).
Microelectrode array (MEA) recordings in brain slices. A high-resolution MEA2100-system (MultiChannel Systems) was used to perform simultaneous extracellular recordings at multiple locations in brain slices. A total of 31 animals were tested in MEA brain slice recordings. The MEA chamber (60pMEA200/30iR-Ti, MultiChannel Systems) in the experiments was composed of a 6-mm-high glass ring and an $8 \times 8$ titanium nitride electrode grid, including 60 electrodes (59 electrodes and 1 internal reference electrode) that cover a recording area of $5 \mathrm{~mm}^{2}$. The electrode diameter was $30 \mu \mathrm{m}$, and electrodes were separated by $200 \mu \mathrm{m}$ distance. The brain slice was placed in the MEA chamber that was perfused with oxygenated aCSF at a rate of $7 \mathrm{ml} / \mathrm{min}$ and maintained at $34^{\circ} \mathrm{C}$. A stabilization time of 5-10 min was given before formal recording. The collected data were analyzed using Multi Channel Analyzer version 2.6.0 (MultiChannel Systems).

In vivo electrophysiological recording. Acute recordings were performed with a custom-built tetrode that allowed for recordings of both single-unit and local field potentials ( $n=5$ for normal and stroke control, respectively, and $n=8$ for experimental groups, respectively). A craniotomy was made $1.3 \mathrm{~mm}$ posterior and $1.7 \mathrm{~mm}$ lateral to the bregma, and recording was made $3.4 \mathrm{~mm}$ inferior to bregma to record from the ventroposteromedial (VPM) nucleus. Extracellular recordings were sampled at $25 \mathrm{kHz}$ using our custom-built NeuroRighter data acquisition system (Rolston et al., 2009). Local field potentials triggered by whisker stimulation were bandpass-filtered $(1-500 \mathrm{~Hz})$ from the raw signal and analyzed offline using custom MATLAB scripts and the Chronux toolbox (Bokil et al., 2010). Single units were detected from the bandpass-filtered $(0.5-5 \mathrm{kHz})$ signal and sorted offline using superparamagnetic clustering (Wave Clus) scripts developed by Quiroga et al. (2004). The contralateral whiskers were stimulated at $\sim 5 \mathrm{~Hz}$ for $10 \mathrm{~s}$ that alternated with ipsilateral whisker stimulation trials as a control for at least 5 repeated trials each during a recording session.

\section{Behavioral tests}

Adhesive removal test. To evaluate sensorimotor function, time for a mouse to remove adhesive pads from the paws was measured as previously described (Bouet et al., 2009; Z. Z. Wei et al., 2015). In brief, a small adhesive dot was placed on forepaws, and the time needed to contact and remove the sticker from each forepaw was recorded. Mice were trained three times before stroke surgery, and the average time was used in data analysis. Animals with response time of $>120$ s were considered insensitive to the tactile stimulus and were excluded from further examinations. Sham control, stroke control, and stroke plus CTZ groups contained 10 or 12 animals in the control groups and 12 or 16 animals in experimental groups. The same animals were also tested in the following tests.

Reach and grasp test. This reaching and grasping performance tests the coordination of forelimb motor functions in rodents. Mice were placed in a cage of $11.4 \times 6.4 \times 3.8 \mathrm{~cm}$. In the front wall of each cubicle, there is a hole of $9 \mathrm{~mm}$ and through which a feeding plane can be accessed. On the feeding plane, small food pellets (2-3 mm diameter) were placed $1.5 \mathrm{~cm}$ from the wall in such a way that the mice can withdraw the food only by reaching out one of its forepaws. Before the experiment, the animals were subjected to mild fasting with $12 \mathrm{~h}$ diet withdrawal. The animal's attempt to reach food pellets and successful retrieval attempts were counted during a $2 \mathrm{~min}$ period after placing the food pellets. The successful ratio of food grasping was then calculated and compared between groups.

Corner test. The corner test was performed $1 \mathrm{~d}$ before ischemia and $3 \mathrm{~d}$ after ischemia, as described previously (Zhang et al., 2002; Choi et al., 2012). Two cardboard plates $(30 \mathrm{~cm} \times 20 \mathrm{~cm} \times 0.3 \mathrm{~cm})$ were attached at a $30^{\circ}$ angle from each other in a home cage. Each subject mouse was placed between the two plates and allowed to freely move to the corner. The number of right and left turns was counted. Twenty trials/tests were performed for each mouse.

Cylinder test. The mice were placed in a glass cylinder $(9.5 \mathrm{~cm}$ diameter and $11 \mathrm{~cm}$ height), and the number of times each forelimb or both forelimbs were used to support the body on the wall of the cylinder was counted for $5 \mathrm{~min}$. The animals were evaluated at different days after stroke. Two mirrors were placed behind the cylinder to view all directions. The number of impaired and nonimpaired forelimb contacts was calculated as a percentage of total contacts. 
Open field test. In the open-field test, mice were allowed to freely move $(25 \mathrm{~cm} \times 30 \mathrm{~cm} \times 25 \mathrm{~cm})$ during the dark cycle. Mild stress was induced by exposure to an open-field animal cage-like box. The container was divided into 30 equal $5 \times 5$ squares, and the number of line crossings and duration of stay by each animal were recorded and calculated during the first exposure measured for $2 \mathrm{~min}$. The middle 12 squares were considered the inner space, whereas the other 18 squares were considered the boarder space. The calculation for the relative stress-induced anxiety was performed in double-blinded manner using the total stay duration in boarder space in each 2 min.

Whisker-touching behavior. Repetitive whisker-touching behavior is a reflection of the intact neuronal controls of the barrel cortex-thalamuswhisker pathway. In stroke animals repaired with LMO3 cell transplantation, activation of the LMO3 protein and the whisker-touching reaction can be achieved by acute application of intranasal CTZ. CTZ (2 $\mathrm{mg} / \mathrm{kg}$ ) was intranasally delivered, and the duration of whisker-touching behaviors was counted $5 \mathrm{~min}$ after CTZ application. This delay helps to avoid counting false-positive reactions due to the animal's reaction to the local sensation on the nose. The counting lasts for $5 \mathrm{~min}$. The ratio of the touching activity before and after CTZ is calculated and expressed.

\section{Statistical analysis}

For comparison between two groups, we used the Student's two-tailed $t$ test. Prism version 5.0 (GraphPad) was used to make graphs and to perform statistical analysis. Multiple comparisons were done using oneway or two-way ANOVA followed by Tukey's test or Bonferroni's correction for multiple pairwise comparisons. Nonparametric MannWhitney's $U$ test was applied to electrophysiological and behavioral examinations of multiple comparisons. The $F$ test was performed to verify an $F$ distribution under the null hypothesis in ANOVA tests of multiple groups and/or time points. All the tests were two-tailed, and the significance level $(p)$ was set at 0.05 . Statistical values, such as $t, F$, and $q$, are reported in Results and/or figure legends. The numbers in the text are reported in the form of mean \pm SEM.

\section{Results}

\section{Neuronal differentiation of LMO3-iPS cells and responses to light and CTZ stimulation}

We established a mouse iPS-cell line that stably expressed the LMO3 fusion protein (LMO3-iPSs). The expression of LMO3 and pluripotency of the cell line were confirmed by the EYFP tag in LMO3 and iPS-cell markers (SSEA-1, Oct 3/4, and Nanog), respectively (Fig. 1A). After the " $4-/ 4+$ " RA neural induction protocol (Bain et al., 1995), these LMO3-iPS cells gained neuronal morphology in EYFP fluorescence-positive cells (Fig. 1B). We characterized electrophysiological properties of LMO3-iPSderived neurons 7-12 d after neural induction. In patch-clamp recordings, membrane depolarization caused the firing of repetitive action potentials in a current injection-dependent manner (Fig. 1C). Similarly, stimulation by both light and the luciferase substrate, CTZ, elicited trains of spikes (Fig. $1 D, E$ ). In the voltage-clamp mode at the $-60 \mathrm{mV}$ holding potential, photostimulation by blue laser light increased occurrence of fast inward currents, resembling EPSCs (Fig. $1 F$ ). The activated neurons were glutamatergic as they were sensitive to block by the glutamate receptor antagonists, CNQX and D-AP5 (Fig. $1 F$ ). We also conducted $\mathrm{Ca}^{2+}$ imaging in LMO3-iPS-derived neurons loaded with the fluorescent $\mathrm{Ca}^{2+}$ indicator, fura-2, using ultraviolet excitation light (Fig. 2A-C). Stimulation with blue light or CTZ increased the intracellular $\mathrm{Ca}^{2+}$ concentration, reminiscent of that induced by high potassium $(15 \mathrm{mM} \mathrm{KCl})$ medium $(\Delta$ ratio $=$ $0.0056 \pm 0.0026,0.0079 \pm 0.0024$, and $0.0133 \pm 0.0028$ for CTZ, light, and $15 \mathrm{mM} \mathrm{K}^{+}$, respectively; $p>0.2$ among groups; oneway ANOVA; $F_{(2,12)}=1.53 ; n=3,8$, and 4 assessments, each included $\geq 30$ cells) (Fig. $2 D-F)$.
Excessive $\mathrm{Ca}^{2+}$ increases may cause excitotoxicity. In LDH release assays, neither of the applied light or CTZ stimuli caused a significant change in cell viability (one-way $\operatorname{ANOVA;} F_{(2,6)}=$ 7.057, $p=0.0265, n=8-10$ assessments in each condition; $q_{(6)}=$ 3.654, $p>0.09$ for control vs laser; $q_{(6)}=1.513, p>0.5$ for control vs CTZ) (Fig. 2G). These experiments indicate that LMO3-iPS cells can be differentiated into functional neurons responsive to both light and CTZ stimulations with increased $\mathrm{Ca}^{2+}$ and action potentials, yet without causing excitotoxicity.

In a control study, cells were transduced with LMO3 or with a point mutation analogous of nonfunctional mutation in the pore region of a channelrhodopsin chimera (D292A in C1/C2) (Kato et al., 2012) that corresponds to D248A in the VChR1 moiety of LMO3. Judged by the YFP fluorescent intensity, the expression level of these channels in cells was similar (Fig. $2 H$ ). A large inward photocurrent was recorded in patch-clamp recordings during photostimulation from cells expressing LMO3 (Fig. 2I), whereas cells expressing LMO3/D248A exhibited negligible photocurrent to the same photostimulation (Fig. $2 I-L$ ).

\section{Expression of neuronal markers in differentiated LMO3-iPS cells}

Neuronal differentiation of LMO3-iPS-NPCs was verified with neuronal fluorescent markers 7-12 d after neural induction. Transfected cells were labeled with EYFP, and their neuronal differentiation was identified by specific markers, including NF, synapsin-1, and NeuN (Fig. 3). Cell counting assays confirmed that $>80 \%$ of total cells expressed $\mathrm{NeuN}$ and/or NF, indicating their neuronal differentiation (Fig. 3D). The forebrain marker FoxG-1 was identified in these cells (Fig. 3E). We observed glutamatergic markers, VGLUT1, localized with the EYFP tag of LMO3 in most differentiated cells (Fig. $3 H$ ), consistent with our electrophysiological recording of glutamatergic currents (Fig. $1 F)$. This was in line with previous reports that the $4-/ 4+\mathrm{RA}$ differentiation protocol primarily induced glutamatergic neural lineage cells (Bibel et al., 2007; Boissart et al., 2013).

\section{Light and CTZ stimulation promoted neurite growth of LMO3-iPS-derived neurons in vitro}

The axon/neurite outgrowth of differentiating LMO3-iPS-NPCs was examined in an axon isolation device that contained compartments of cell bodies and neurites divided by microgrooves. After neural induction, LMO3-iPS-NPCs were plated into the cell body compartment for terminal differentiation. One day after plating, cells were subjected to photostimulation or CTZ exposure for 5 consecutive days. Blue laser light $(10 \mathrm{~Hz}, 15 \mathrm{~min} / \mathrm{ses}-$ sion, 3 sessions/d) was applied through fiber optics, while CTZ $(1.5 \mu \mathrm{M})$ was added into the media for $15 \mathrm{~min}$ ( 3 times/d). The control group contained cells treated with regular medium and without photostimulation. Six days later, Tuj-1 staining identified significantly more axons/neurites that extended cross the microgrooves in the group that received laser light or CTZ treatment (Fig. 4A). The number of neurites extending cross the microgrooves in the AXIS chamber was significantly increased by either light or CTZ stimuli (Fig. $4 B)(n=4$ in each condition; one-way ANOVA followed by Tukey's pairwise comparisons; $F_{(2,3)}=14.26, p=0.029$, control vs laser and $p=0.0319$ control vs CTZ). The light and CTZ stimuli also significantly increased the length of processes extending beyond the microgrooves (Fig. $4 C)\left(F_{(2,3)}=18.15, p=0.0211 ; q_{(3)}=7.146, p=0.0302\right.$ for control vs laser; $q_{(3)}=7.593, p=0.0256$ for control vs CTZ). Moreover, cells stimulated by light exhibited significantly larger process diameters (Fig. $4 D)\left(q_{(27)}=6.797, p=0.0001\right.$ for control 
LMO3 (EYFP)
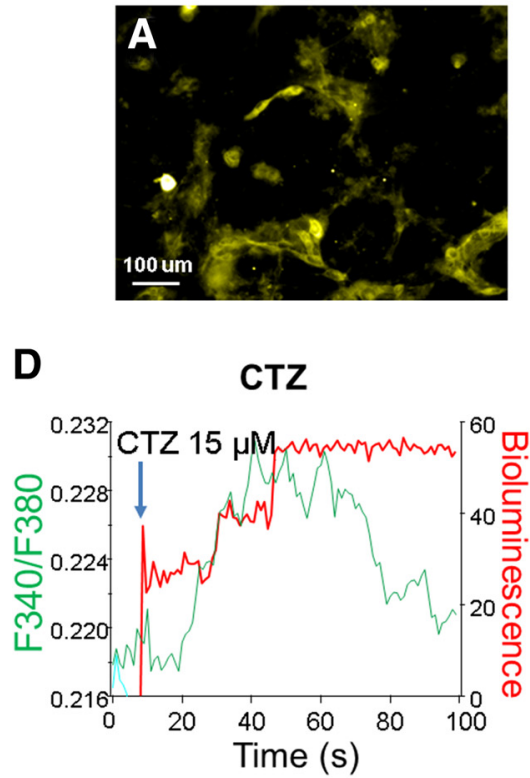

G
Fura 2 (F380)

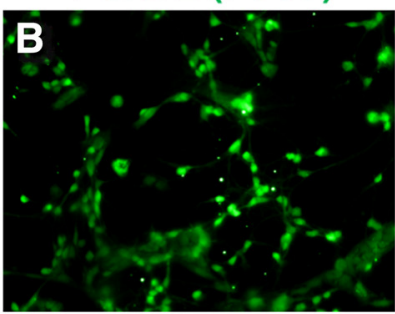

E

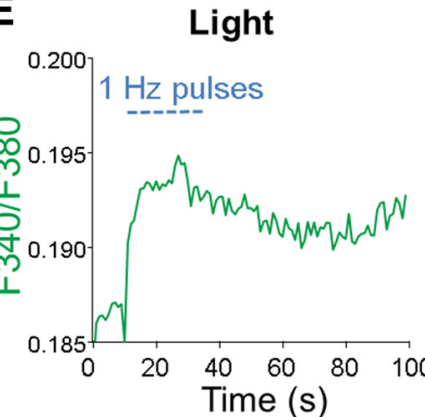

Merged

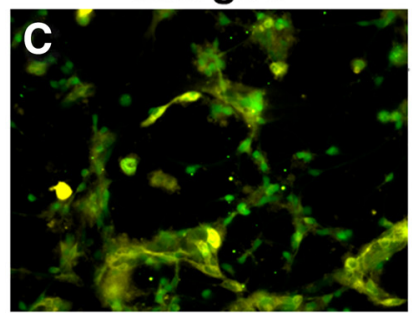

$\mathbf{F}$

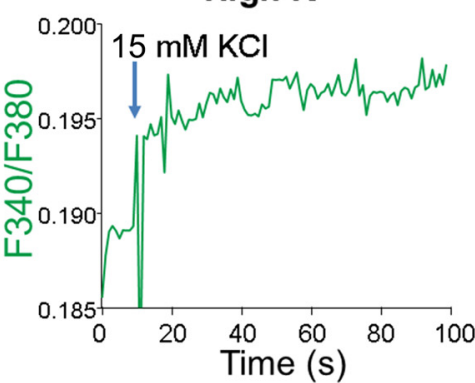

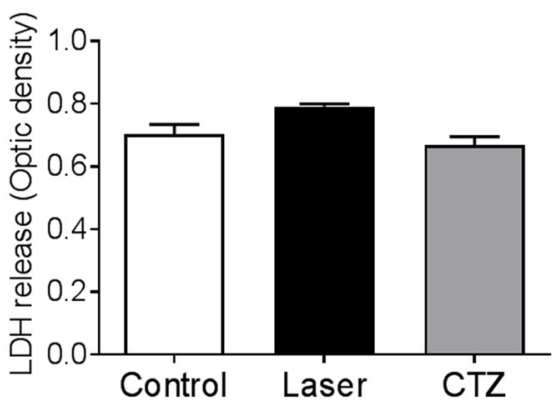

I
$\mathrm{H}$

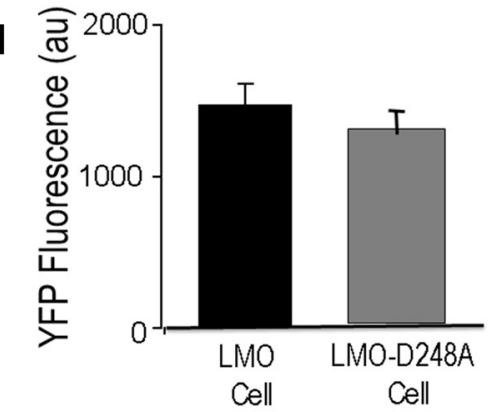

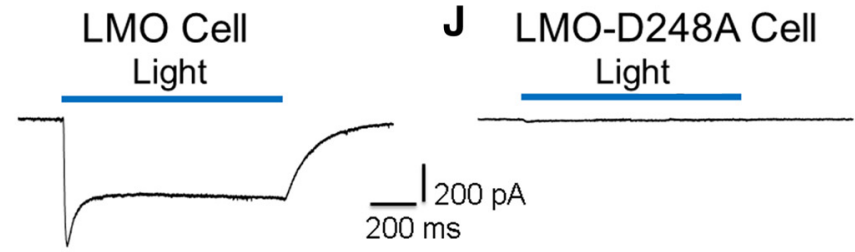
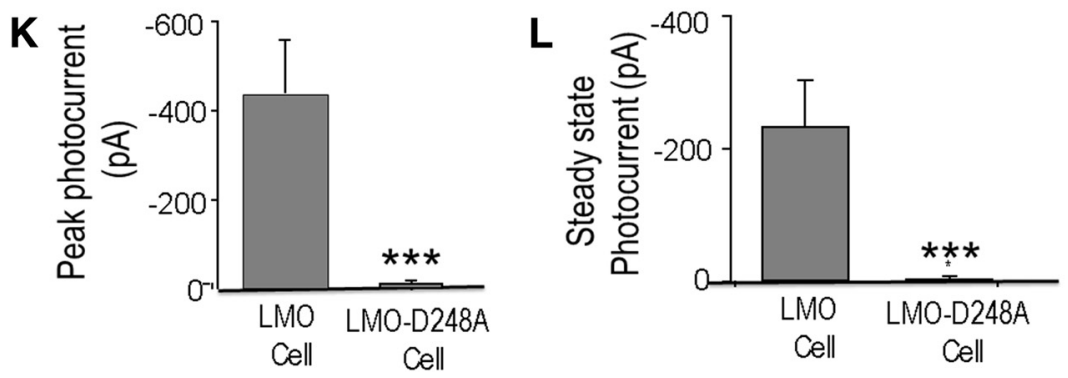

Figure 2. Activation of LM03 channels, $\mathrm{Ca}^{2+}$ influx, and cell viability. LM03 activation-induced cellular consequences, including intracellular $\mathrm{Ca}{ }^{2+}$ increases, and the influence on cell viability were examined in cultures $10-12 \mathrm{~d}$ after neural induction of LM03-iPS-NPCs. $\boldsymbol{A}-\boldsymbol{C}$, Intracellular free $\mathrm{Ca}^{2+}$ concentration was measured using the $\mathrm{Ca}^{2+}$ dye fura-2 AM and $340 / 380$ ratio analysis. The expression of LM03 was demonstrated in cultured cells with the yellow fluorescence of EYFP $(\boldsymbol{A})$. $\boldsymbol{B}$, fura- 2 image of these cells during light stimulation. $\boldsymbol{C}$, Overlay of $\boldsymbol{A}$ and $\boldsymbol{B}$. $\boldsymbol{D}-\boldsymbol{F}$, The time course of intracellular $\mathrm{Ca}^{2+}$ increases induced by bath-applied CTZ (15 $\left.\mu \mathrm{M}, 4-5 \mathrm{~min}\right)$, light stimulation ( $1 \mathrm{~Hz}$ pulse for $4 \mathrm{~min}$ ), and $15 \mathrm{~mm} \mathrm{KCl}$ solution (4-5 min), respectively. All three manipulations caused significant $\mathrm{Ca}^{2+}$ influx and intracellular accumulation. D. The binding of CTZ to the LM03 luciferase, as its substrate, caused the emission of bioluminescence (red) followed by activation of the LM03 and $\mathrm{Ca}^{2+}$ influx event. G, LM03-iPS-NPC-derived neurons were subjected to $5 \mathrm{~d}$ treatments of blue light stimulation ( $10 \mathrm{~Hz}, 15 \mathrm{~min} / \mathrm{session}, 3$ times per day) or CTZ exposure ( $1.5 \mu \mathrm{M}, 15$ $\mathrm{min} /$ session, 3 times per day), and cell viability was measured using the LDH release assay $12 \mathrm{~h}$ after the last stimulation session. There was no significant difference among all three groups ( $n=$ 8-10 per group). $\boldsymbol{H}$, A control experiment of expressing LM03 or LMO-D248A proteins. The latter gene has a point mutation (D248A), which made the channel moiety nonfunctional. The EYFP fluorescence intensity measurement verified similar expression levels in transfected cells. $n=6$ wells each. $I$, $J$, In whole-cell patch-clamp recording, a large inward current was observed during wide-field photostimulation with blue light. Photocurrent to the same photostimulation was negligible in the cell expressing mutant LM03/D248A. Peak and steady-state photocurrents were virtually absent with LM03-D248A. $N=5$ cells each. $\boldsymbol{K}$, $\boldsymbol{L}$, Summery of the patch-clamp data, showing the CTZ-induced peak and steady-state currents in different cells. ${ }^{* * *} p<0.001$ versus $L$ M03 cells (Student's $t$ test). 
A

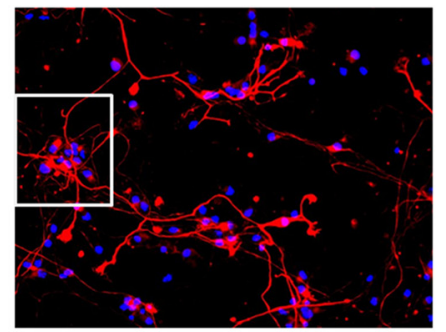

Hoechst 33342 NF

B

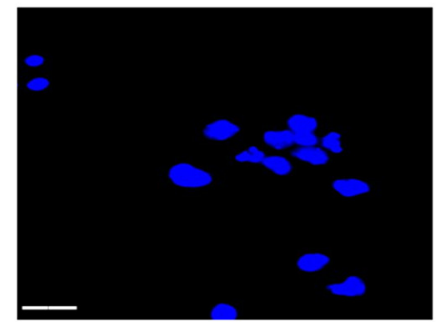

Hoechst 33342

C

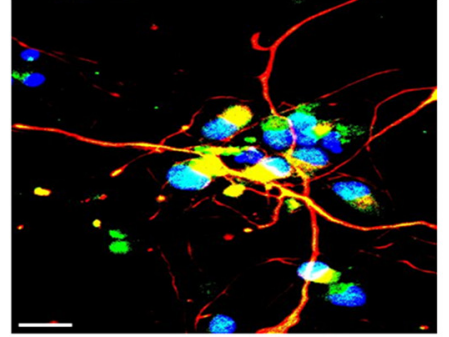

Hoechst 33342 NFEYFP

F

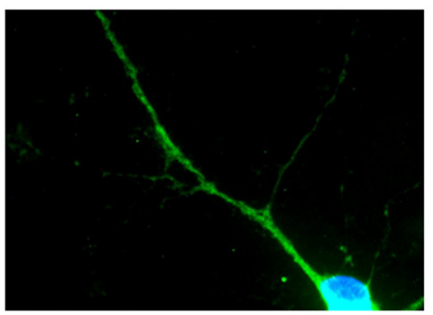

Hoechst 33342 EYFP

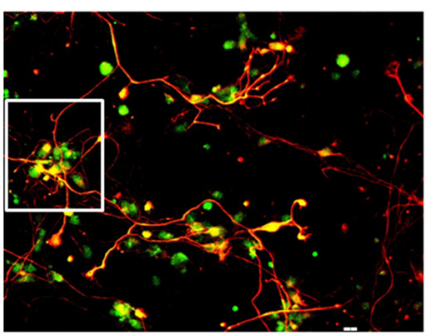

NF EYFP

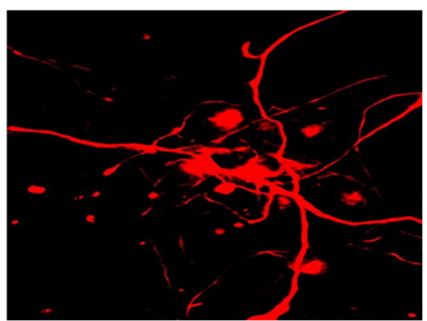

NF
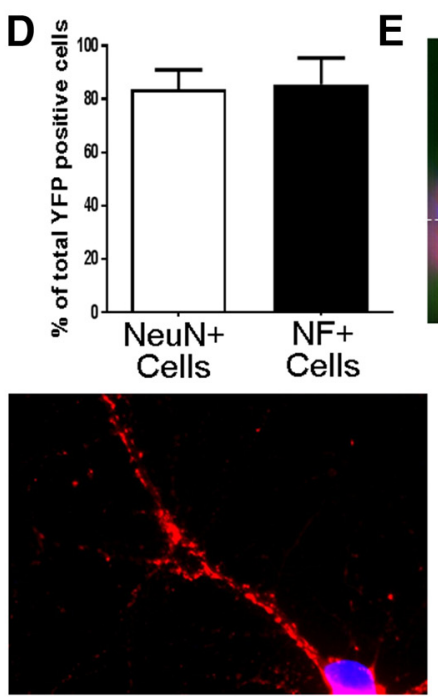

Hoechst Synapsin-1

E

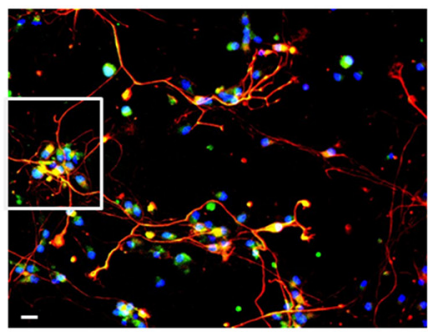

Merge

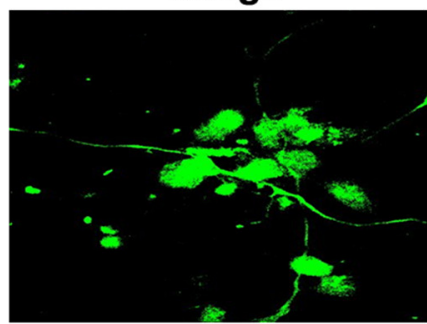

EYFP

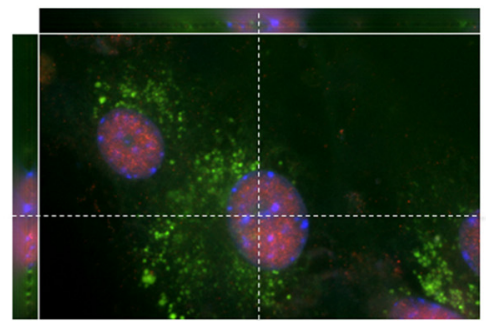

EYFP FoxG-1

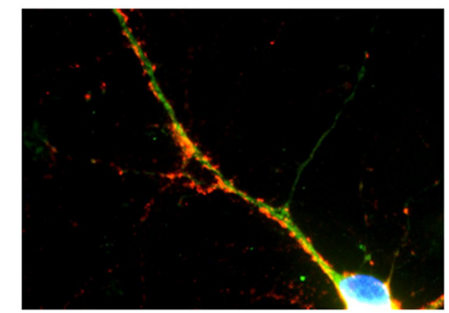

Hoechst Synapsin-1 EYFP
G

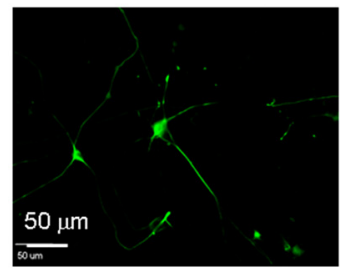

EYFP

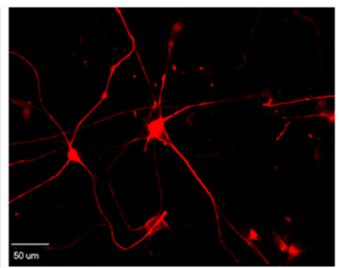

NF

H

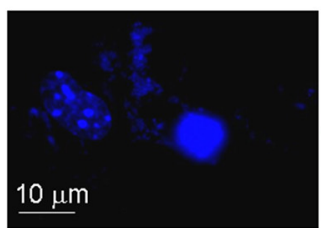

Hoechst

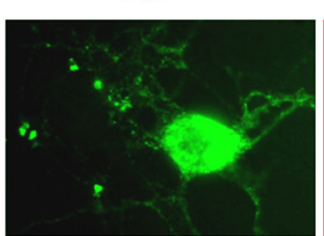

EYFP

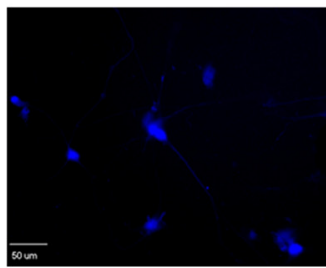

NeuN

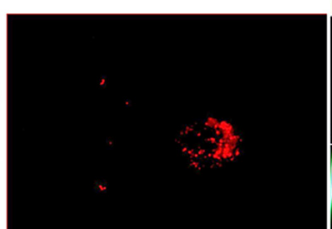

vGLUT-1

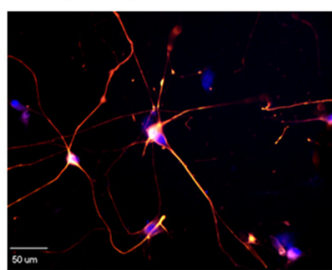

Merge

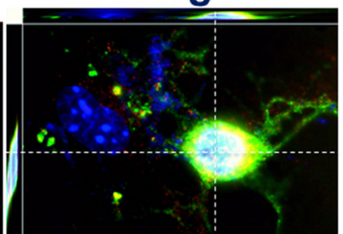

Merge

Figure 3. Neuronal differentiation of LM03-iPS cells. LM03-iPS-NPCs were subjected to the "4-/4+" RA differentiation protocol. Immunohistochemical staining was performed for neuronal markers 7-12 d later. $\boldsymbol{A}$, The LM03 expression was verified by EYFP tagged to the virus construct. NF labeling (NF) (red) shows the neurite growth from differentiated cells marked with the EYFP fluorescence (green). The merged image demonstrates neuronal differentiation of transfected cells. $\boldsymbol{B}, \boldsymbol{C}$, Enlarged images from the frame in $\boldsymbol{A}$. $\boldsymbol{C}$, The overlay of the three images in $\boldsymbol{B}$, showing neuronally differentiated cells. D, Quantified data demonstrate $>80 \%$ of cells expression the neuronal marker NF and NeuN (see $\boldsymbol{G}$ ). $\boldsymbol{E}$, The confocal image illustrates that LM03 expressing cells express the forebrain marker FoxG-1.F, The three high-magnification images illustrate the presynapse protein synapsin-1 in a differentiated iPS cell. $\mathbf{G}$, Many differentiated cells (EYFP, green) were positive to NF as well as the mature neuronal marker NeuN (blue). The merged image represents a complete overlay of the three markers. $\boldsymbol{H}$, These neurons also expressed glutamatergic neuronal markers, including vesicular glutamate transporter 1 (VGLUT1) and VGLUT2 (data not shown due to space limitation). 
A
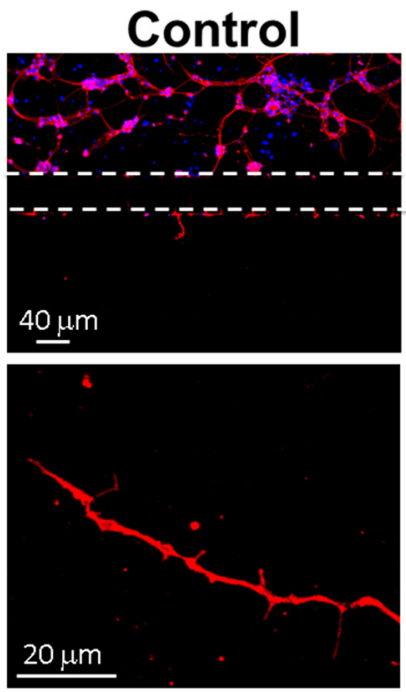

B

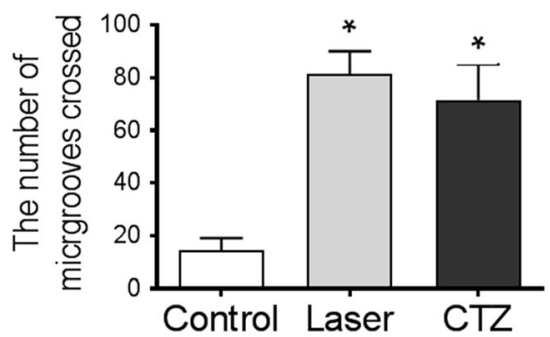

D

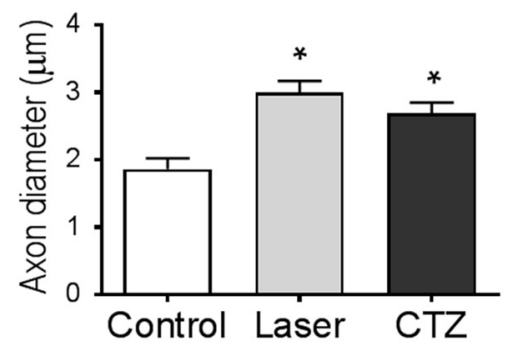

Laser light
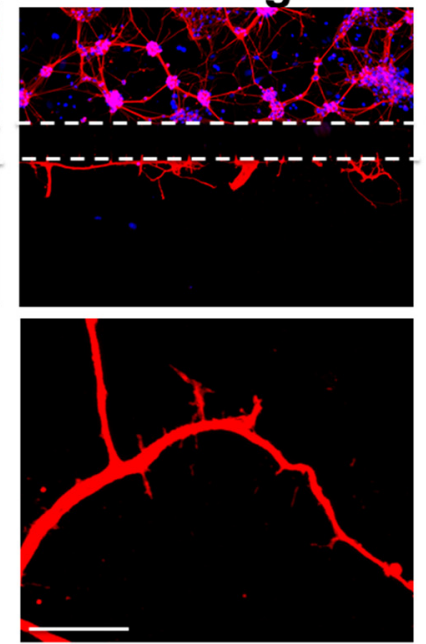

CTZ
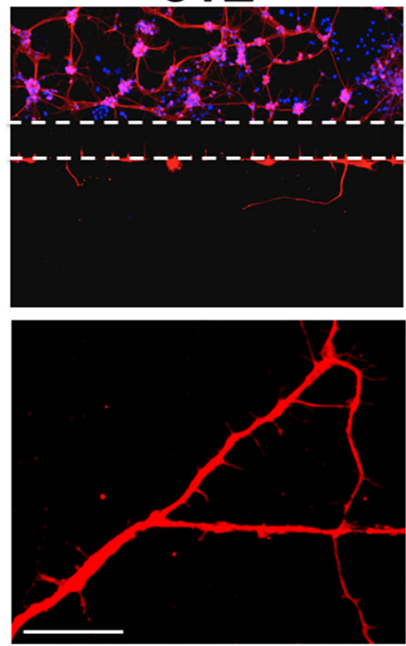

C

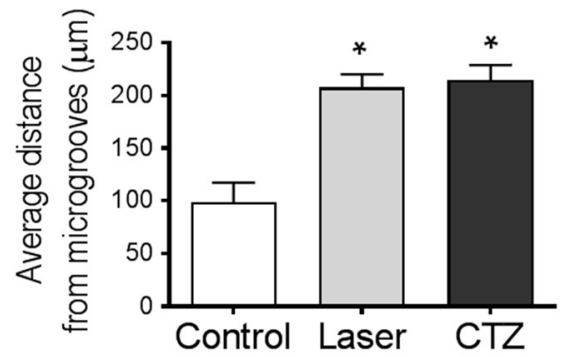

E

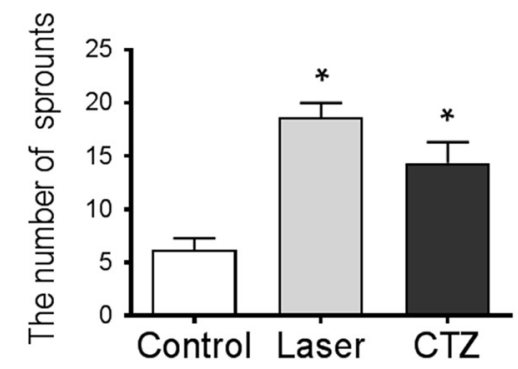

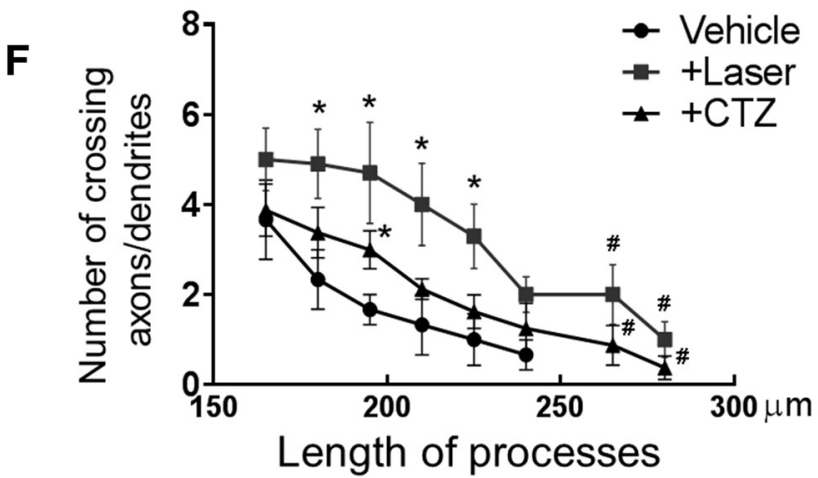

Figure 4. Light and CTZstimulation promoted neurite growth of LMO3-iPS-NC-derived cells. A, LM03-iPS-NPCs were plated in AXIS axon isolation device after "4-/4+" differentiation. One day after plating, cells in the laser group received blue light $(10 \mathrm{~Hz}, 15 \mathrm{~min})$ three times a day for 5 consecutive days. Cells in the CTZ group were exposed to CTZ (1.5 $\mu \mathrm{m}, 15 \mathrm{~min})$ three times a day for $5 \mathrm{~d}$. Cells in the control group received CTZ-free medium changes and also served as the light off control. Six days after plating, cells were stained with TUJ-1. Dashed lines in lower-magnification images outline the microgrooves in the AXIS device, which separated the cell body and processes. Higher-magnification images represent samples of processes in each group. $\boldsymbol{B}-\boldsymbol{E}$, Quantified neurite analysis shows the number of neurites extending across the microgrooves in the AXIS chamber $(\boldsymbol{B})$, the average distance that neurites extend beyond the microgrooves $(\boldsymbol{C})$, the average diameter of neurites $(\boldsymbol{D})$, and the number of process sprouts $(\boldsymbol{E})$. Either blue light stimulation or CTZ exposure significantly increased neurite growth and maturation compared with those in the control group. $n=4$ independent assays. For detailed statistical results, see text. $\boldsymbol{F}$, Results of the Sholl analysis using the ImageJ software. The number of neurites that extended and crossed the microgroove barrier into the axonal chamber was counted at different distances from microgrooves, and their length was measured. In the control group, fewer crossings took place compared with laser and CTZ groups. Neurites in the control group grew shorter than neurites in laser light and CTZ groups. ${ }^{*} p<0.05$ versus controls (two-way ANOVA). ${ }^{*} p<0.05$ versus the maximal length of control axons (two-way ANOVA). $n=4$ per group. 

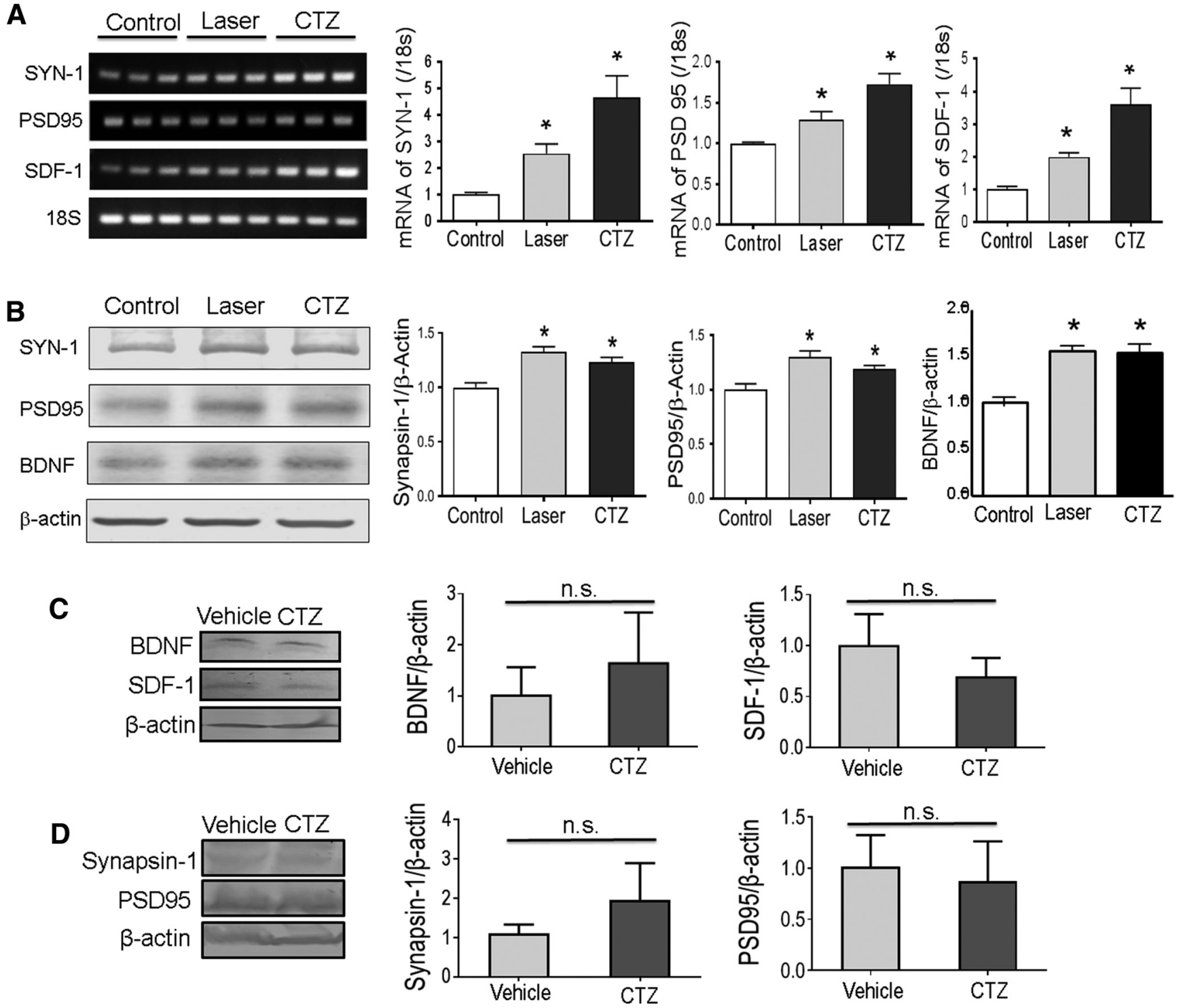

$\mathbf{E}$

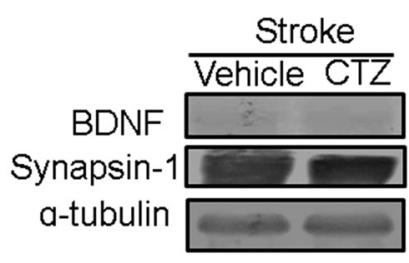

$\mathbf{F}$

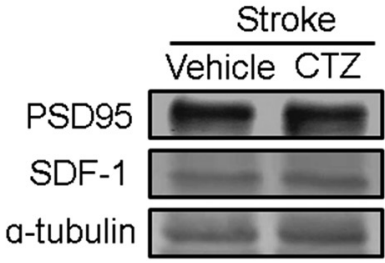

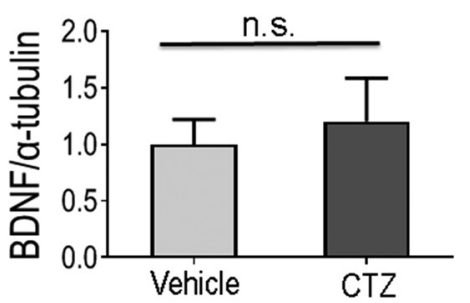
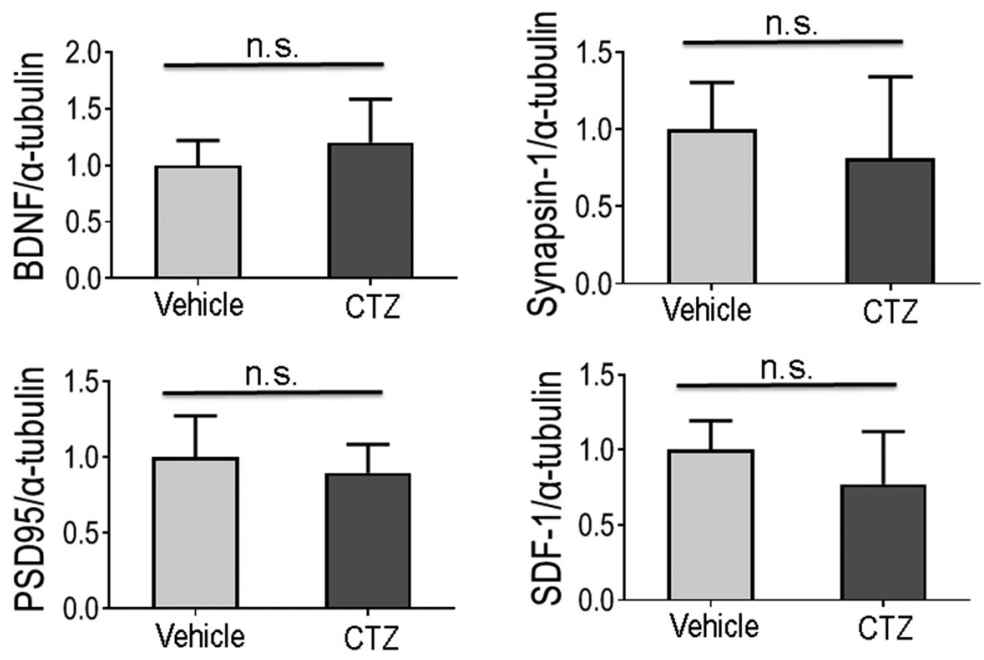

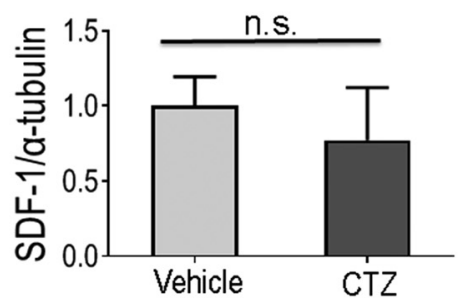

Figure 5. Light and CTZ stimulation increased gene expression in LM03-PPS-derived neurons in vitro. Cultured LM03-PPS-derived cells received chemogenetic and optogenetic stimulation from 1 to 5 dafter neural induction, RT-PCR, and Western blot were performed at $6 \mathrm{~d}$ after induction. $A$, Representative images of RT-PCR gels indicate the expression of synaptic maker synapsin-1 (SYN-1), PSD95, and growth factor SDF-1 in each group. The mRNA level of each marker was normalized against 18 S. Cells that received photostimulation (blue light, $10 \mathrm{~Hz}, 15$ min, three times a day for 5 consecutive days) in the laser group and those in the CTZ treatment group (1.5 $\mu \mathrm{M}, 15 \mathrm{~min}$, three times a day for $5 \mathrm{~d}$ ) had significantly higher mRNA levels of SYN-1, PSD95, and SDF-1 (for statistical analysis, see text). B, Represented images of Western blot bands of SYN-1, PSD95, and BDNF. Quantified data show that blue light in the laser group or (TZ (Figure legend continues.) 
vs light; $q_{(27)}=4.855, p=0.0053$ for control vs CTZ) as well as increased number of sprouts (Fig. 4E) (nonparametric Mann-Whitney test, $p=0.0001$ laser light off control vs light; $p=0.0072$ control vs CTZ). There were no statistical differences between light and CTZ groups. Consistent with above analyses, the Sholl analysis validated that the number of processes at $200 \mu \mathrm{M}$ from microgroves and the maximal length of processes was significantly greater in two treatment groups compared with controls (Fig. $4 F$ ).

\section{Light and/or CTZ stimulation upregulated synaptic proteins and BDNF in LMO3-iPS-NPCs}

Twelve hours after stimulation with laser light or CTZ (6 d into the terminal differentiation), RT-PCR showed that lightstimulated LMO3-iPS-NPCs expressed more mRNA of synapsin-1 $\left(q_{(18)}=4.025\right.$, $p=0.0276, n=4$; one-way ANOVA followed by Tukey's pairwise comparisons), $\operatorname{PSD} 95\left(q_{(18)}=4.556, p=0.0125, n=4\right)$, and SDF-1 $\left(q_{(18)}=5.405, p=0.0034, n=4\right)$ (Fig. $\left.5 A\right)$. CTZtreated LMO3-iPS-NPCs also showed significantly higher mRNA levels of synapsin-1 $\left(q_{(18)}=6.982, p=0.0003, n=4\right)$, PSD95 $\left(q_{(18)}=7.578, p=0.0001\right)$, and SDF-1 $\left(q_{(18)}=8.72, p<0.0001\right)$ (Fig. 5A). Western blot analysis verified higher protein levels of synapsin-1 $\left(q_{(17)}=7.334, p=0.0003\right.$ for control vs laser; $q_{(17)}=$ $5.213, p=0.0059$ for control vs CTZ), PSD95 $\left(q_{(17)}=6.027, p=\right.$ 0.0014 for control vs laser; $q_{(17)}=3.685, p=0.0462$ for control vs CTZ), and BDNF $\left(q_{(14)}=9.6, p<0.0001\right.$ for control vs laser; $q_{(14)}=8.868, p<0.0001$ for control vs CTZ) in LMO3-iPS-NPCs that received either photostimulation or CTZ stimulation compared with sham controls ( $n=4$ each group) (Fig. $5 B$ ). In cells without the expression of LMO3 channels, the same CTZ applications did not show significant influence on these factors (Fig. $5 C, D)$. Examined in additional controls in vivo studies, CTZ treatment in stroke animals received iPS-NPCs of no LMO3 expression failed to induce significant influence on tested factors (Fig. $5 E, F)$.

\section{Validation of intranasal delivery of CTZ with in vivo bioluminescence imaging}

For the translational potential of the optochemogenetic approach, we tested noninvasive brain delivery of CTZ via the welldefined nasal-brain route. Normal mice received stereotaxic injection of AAV vector carrying the LMO3 gene into the right

\footnotetext{
$\leftarrow$

(Figure legend continued.) exposure increased the protein levels of these factors (for nonparametric statistical analysis, see text). $n=4$ /group independent assays. $\boldsymbol{C}, \boldsymbol{D}$, Western blot analysis on the expression levels of BDNF, SDF-1, synapsin-1, and PSD-95 in the cortical cultures with no LM0-3 transduction. This test served as a negative control for possible off-target actions of CTZ. There was no significant difference among saline and CTZ groups (unpaired Student's $t$ test, $p>0.05, n=4$ cultures per group). $\boldsymbol{E}$, $\boldsymbol{F}$, Western blot analysis of the expression of BDNF, synapsin-1, PSD-95, and SDF-1 in the peri-infarct region $7 \mathrm{~d}$ after stroke. CTZ (intranasal delivery of $2 \mathrm{mg} / \mathrm{kg} / \mathrm{d}$, starting from $8 \mathrm{~d}$ after stroke) or vehicle treatment for 14 consecutive days. There was no significant difference of the expression of BDNF, SDF-1, synapsin-1, and PSD-95 in the peri-infarct region between the two groups at the end of the treatments. $n=5 /$ group. $p>$ 0.05 (unpaired Student's $t$ test). ${ }^{*} p<0.05$ versus controls (one-way ANOVA).
}

barrel cortex. Postmortem histology confirmed proper targeting of the barrel cortex with LMO3 as shown in the EYFP expression surrounding the injection site (Fig. 6B). After intranasal administration of CTZ (50 $\mu \mathrm{g}$, or $2.0 \mathrm{mg} / \mathrm{kg}$ ), bioluminescence was observed in the area of LMO3 expression and decayed over the next hour (Fig. 6A,C).

In adult stroke mice of focal cerebral ischemia targeting the right sensorimotor cortex, LMO3-iPS-NPCs were transplanted into the core and peri-infarct regions $7 \mathrm{~d}$ after stroke (Fig. 6D). Fourteen days later, transplanted cells and functional expression of LMO3 in these cells were confirmed with in vivo bioluminescence imaging (Fig. 6E). Bioluminescence was detected in the cell graft area and remained visible for $\sim 1 \mathrm{~h}$ after intranasal CTZ administration (Fig. 6F).

\section{CTZ stimulation of grafted LMO3-iPS-NPCs promoted neuronal differentiation, axonal remyelination, and long- term survival in the ischemic brain}

In the ischemic stroke mice receiving cell transplantation or control medium, repeated stimulation of transplanted LMO3-iPSNPCs was achieved by intranasal CTZ treatment $(2 \mathrm{mg} / \mathrm{kg}, 10 \mu \mathrm{l})$ twice a day for 2 weeks starting $1 \mathrm{~d}$ after transplantation. Three weeks after stroke ( 2 weeks after cell transplantation), grafted LMO3-iPS-NPCs were identified by EYFP or mCherry tag of LMO3 (Fig. 7A-C). Colocalization with NeuN was observed in many EYFP- or mCherry-positive cells, indicating neuronal differentiation (Figs. 7A-C, 8A). Stroke animals showed a significant reduction in the expression of $\mathrm{MBP}$ in the peri-infarct region $\left(q_{(20)}=15.48, p<0.0001\right.$ for sham vs stroke) (Fig. $\left.7 D, E\right)$. The MBP expression was noticeably greater in mice of the Stroke+LMO3-iPS + CTZ group (one-way ANOVA, $q_{(20)}=$ $7.679, p=0.0003$ for Stroke vs Stroke +LMO3-iPS +CTZ; $q_{(20)}=$ $4.521, p=0.026$ for Stroke+LMO3-iPS vs Stroke+LMO3iPS +CTZ; $n=5-8$ per group) (Fig. $7 E$ ). Consistent with these observations, 1 month after stroke ( 3 weeks after cell transplantation), EYFP-positive cells colabeled with the intact nucleus of Hoechst 33342 were identified as surviving transplanted cells. In cell counting assays, stroke animals in the Stroke+LMO3-iPS + CTZ 
mCherry NeuN Hoechst
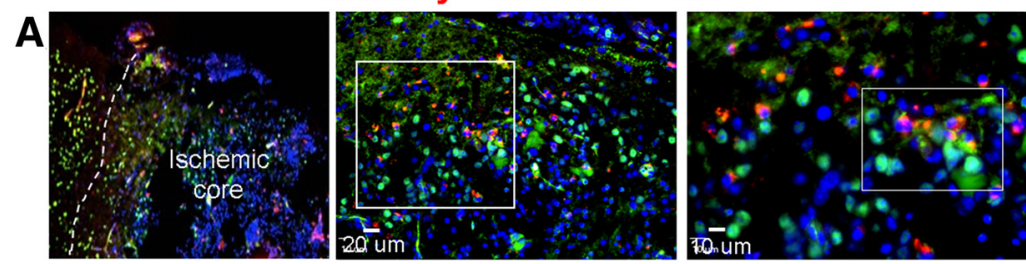

B
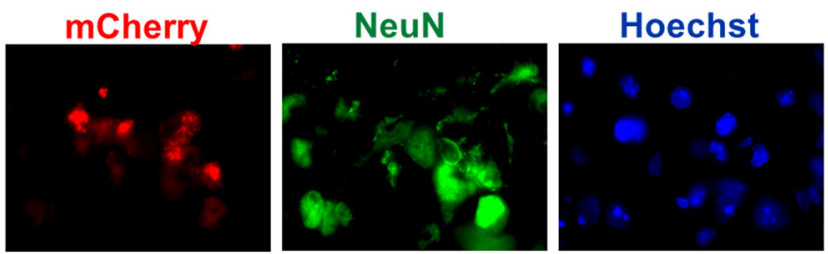

Merge
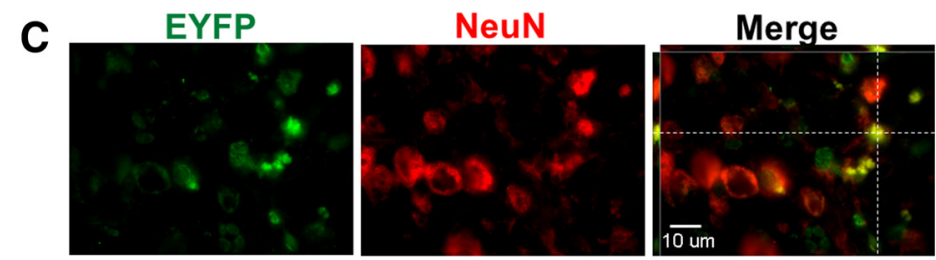

D
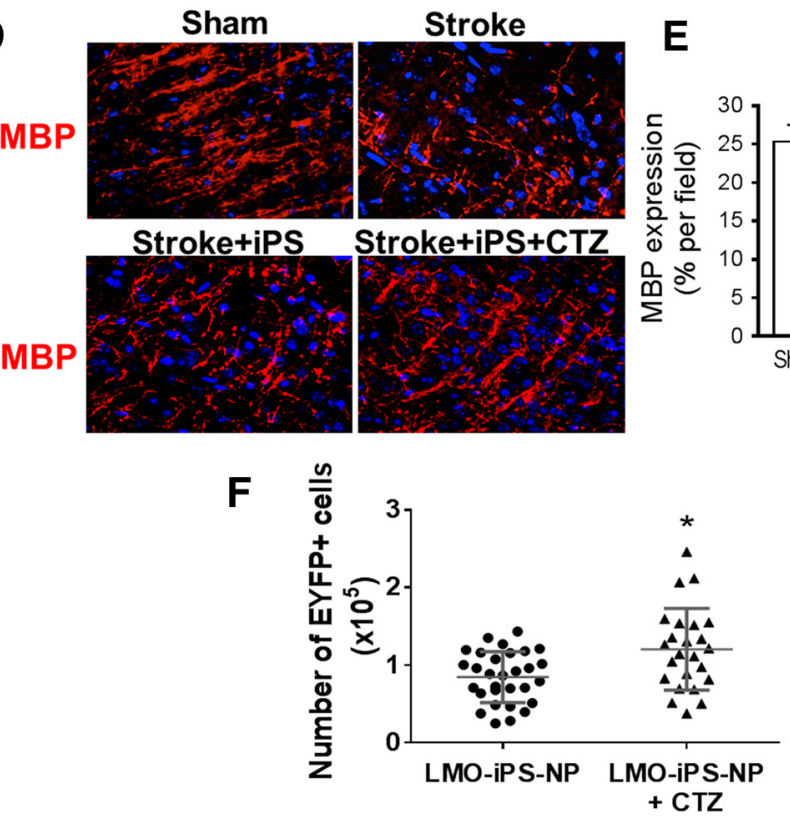

Figure 7. Neuronal differentiation of transplanted LM03-iPS-NPCs and CTZ treatment promoted remyelination in the ischemic brain. Transplantation of LM03-iPS-NPCs was performed $7 \mathrm{~d}$ after stroke. At various later time points, immunohistochemical staining examined the fate of transplanted cells in the ischemic cortex. $\boldsymbol{A}$, Twenty-one days after transplantation, immunostaining of the ischemic core and peri-infarct cortical regions identified transplanted cells positive with mCherry tagged LM03. The three images show mCherry-positive (red) and NeuN-positive (green) cells at different magnifications. $\boldsymbol{B}$, Enlarged images of the frame in the last image in $\boldsymbol{A}$. Right, 3D image represents the overlay of mCherry and NeuN staining. $\boldsymbol{C}$, In confocal imaging, EYFP fluorescence was from the EYFP tagged to the LMO3 construct; its colocalization with NeuN in the peri-infarct region verified again the survival and neuronal differentiation of grafted LM03-iPS-NPCs 3 weeks after transplantation. $\boldsymbol{D}$, In stroke mice that received LM03-iPS-NPC transplantation, CTZ (2 mg/kg) was intranasally administered $1 \mathrm{~d}$ after cell transplantation for 14 consecutive days. Three weeks later, the expression of MBP (red) in the peri-infarct region was examined for myelination. In this assay, Hoechst 33342 counterstaining (blue) was used to label all cells in the peri-infarct region. $\boldsymbol{E}$, Bar graph represents the relative expression of MBP per field. Stroke alone caused a significant reduction in MBP expression compared with that in sham group. More MBP staining appears in the LM03-iPS-NPC and LM03-iPS-NPC plus CTZ groups. $n=5-8 /$ group. ${ }^{*} p<0.05$ versus sham control (one-way ANOVA). ${ }^{\#} p<0.05$ versus stroke (one-way ANOVA). ${ }^{\Delta_{p}}<0.05$ versus stroke + LM03 cells (one-way ANOVA). For detail statistical analysis, see text. $\boldsymbol{F}$, Long-term survival of transplanted cells in the poststroke brain. Cell counting was performed 1 month after stroke ( 3 weeks after cell transplantation). EYFP-positive cells colabeled with the intact nucleus of Hoechst 33342 were identified as surviving transplanted cells. For each animal, 30 brain sections spanning the ipsilateral cortex were counted. Cell counting was performed in the ischemic core and peri-infarct transplanted regions. ${ }^{*} p=0.0034$ (paired $t$ test, $F=2.569, \mathrm{DFn}=$ $23, \mathrm{Dfd}=29$ ). $n=30$ animals in the LM03-iPS-NPC group (no CTZ control) and 24 animals in the LM03-iPS-NPC plus CTZ treatment group. group showed increased surviving transplanted cells compared with animals received LMO3-iPSs but no CTZ treatment (unpaired Student's $t$ test, $p=0.0034$ for Stroke+LMO3-iPS vs Stroke+LMO3iPS+CTZ; $F=2.569, n=30$ and 24 animals, respectively) (Fig. $7 F$ ).

There were increased numbers of BrdU/NeuN double-positive cells (oneway ANOVA followed by Tukey's pairwise comparisons; $q_{(25)}=8.257, p<$ $0.0001)$ and BrdU/Glut-1 double-positive cells $\left(q_{(20)}=6.081, p=0.0018\right)$ after stroke compared with that in the sham group, indicating pronounced neurogenesis and angiogenesis (Fig. 8). Stroke animals receiving cell transplantation (Stroke+LMO3-iPS) or a combination of transplantation and CTZ stimulation (Stroke+LMO3-iPS + CTZ) showed even greater numbers of $\mathrm{BrdU} / \mathrm{NeuN}$ and BrdU/Glut-1 double-positive cells compared with those in the Stroke-only group $\left(\mathrm{NeuN}: q_{(25)}=4.129, p=0.0519\right.$ for Stroke vs Stroke+LMO3-iPS; $q_{(25)}=$ 7.635, $p=0.0001$ for Stroke vs Stroke+ LMO3-iPS+CTZ; Glut-1: $q_{(20)}=4.079$, $p=0.0419$ for Stroke vs Stroke+LMO3iPS; $q_{(20)}=4.06, p=0.0431$ for Stroke vs Stroke+LMO3-iPS+CTZ) (Fig. 8C,E), indicating that poststroke regeneration could be promoted by LMO3-iPS-NPCs. CTZ treatment after LMO3-iPS-NPC transplantation showed a trend of further increasing BrdU/NeuN-positive cells (Fig. 8C).

\section{Synapse formation of transplanted}

LMO3-iPS-NPCs and synaptic activity/ plasticity induced by light or CTZ stimulation on brain slices

Whole-cell patch-clamp recordings in brain slices 4 weeks after stroke showed current injection evoked trains of action potentials in LMO3-expressing cells marked with EYFP (Fig. 9A). Photostimulation with blue laser light (473 nm, 33.6 $\mathrm{mW}$ ) also induced membrane depolarization and action potentials (Fig. 9B). Bath application of CTZ (300 $\mu \mathrm{M})$ significantly increased the firing frequency of spikes compared with vehicle (Fig. 9C,D).

Immunogold EM was performed to identify synapses. LMO3-expressing cells were visualized with electron-dense gold particles by immunostaining against the EYFP tag of LMO3. The ultrastructural imaging on the brain section 4 weeks after stroke revealed synapses between immunogold-positive transplanted cells and immunogold-negative host neurons. Transplanted cells were identified either as presynaptic (Fig. 9E) or postsynaptic with host cells (Fig. 9F) as well as between 
transplanted cells (Fig. 9G). Presynaptic immunogold was primarily found in Type 1 synapses with characteristic asymmetric postsynaptic density (Palay, 1956), consistent with the identity of transplanted cells as glutamatergic neurons.

\section{Optochemogenetic stimulation of grafted LMO3-iPS-NPCs triggered synaptic plasticity in the ischemic cortex}

To validate integration of transplanted LMO3-iPS-NPCs into neuronal networks, spontaneous EPSCs (sEPSCs) were recorded from LMO3-negative resident neurons under whole-cell voltage clamp. The frequency of sEPSCs significantly increased by $\sim 2$-fold during bath application of CTZ $(300 \mu \mathrm{M})$ with no significant change in the amplitude, indicating that CTZ caused neurotransmitter release from surrounding LMO3-iPS-NPCs (Fig. 10A-E).

Stroke in the sensorimotor cortex damages connections of the barrel cortexthalamus pathway and causes secondary cell death in the thalamus (Carmichael et al., 2001; L. Wei et al., 2004). Brain slices from stroke animals that received LMO3iPS-NPCs (4 weeks after stroke) were examined using the MEA containing 59 recording electrodes. The electrode template was placed in the area covering the somatosensory cortex, including part of the ischemic core and peri-infarct regions (Fig. 10F). One of the 59 electrodes located 200-400 $\mu \mathrm{m}$ distance from the edge of the ischemic core was the stimulation electrode. Field EPSPs (fEPSPs) were evoked by electric pulses $( \pm 1500 \mathrm{mV}, 0.1$ ms, once every $30 \mathrm{~s}$ ) and were simultaneously monitored in different brain areas. Among all recording locations, fEPSPs could usually be captured in 18 areas of the peri-infarct and nonischemic regions. Certain fEPSPs significantly enhanced during bath application of CTZ (100 $\mu \mathrm{M}$, 5 min; 7 slices from 4 mice) (Fig. 10G). Heat maps showed that CTZ significantly increased fEPSP responses at several locations (Fig. $10 H, I$ ). In the response heat map generated from MEA recordings, neurons in the cortical layer II/III and V in the same cortical/barrel column responded strongly and showed CTZinduced LTP (Fig. 10H). In addition, neurons at a $400-600 \mu \mathrm{m}$ distance in a different cortical/barrel column also displayed strong response and augmented LTP (Fig. 10H). Marked potentiation of fEPSPs persisted, even after washing out of CTZ, and progressed for at least $30 \mathrm{~min}$ at the end of recordings (Fig. 10J). In the same or different brain slices, photostimulation $(473 \mathrm{~mm}, 10 \mathrm{~Hz}$ for $10 \mathrm{~s}$, separated by $10 \mathrm{~s}$ intervals, 4 min total) triggered similar potentiation effects durgroup.
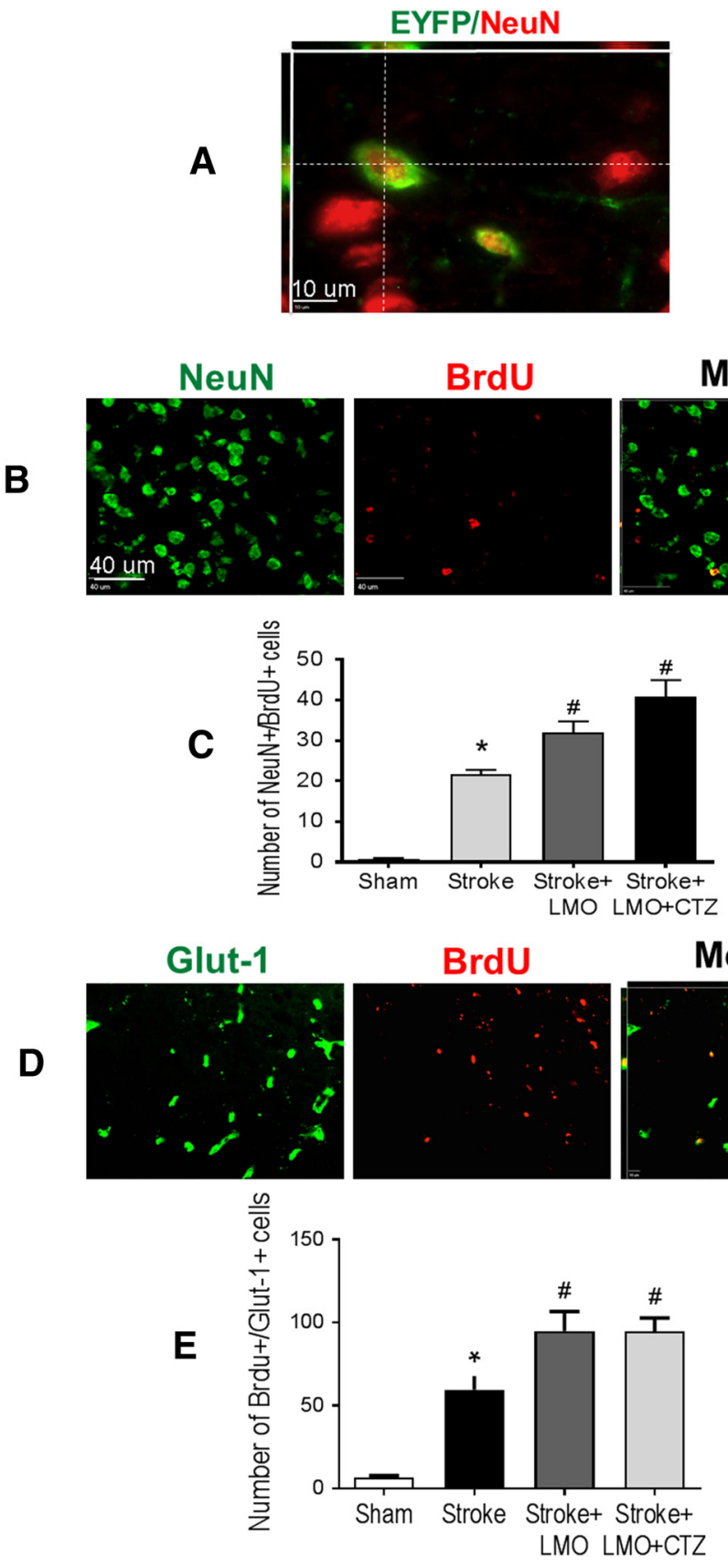

Figure 8. Neurogenesis and angiogenesis in the poststroke brain received different treatments. Immunohistochemical staining of neuron or vessel markers and BrdU incorporation were applied to detect newly formed neuronal and vascular cells in the cortical peri-infarct region $21 \mathrm{~d}$ after stroke with different treatments. BrdU (50 mg/kg, i.p.) was injected $1 \mathrm{~d}$ after cell transplantation for $14 \mathrm{~d}$. $\boldsymbol{A}$, The 3D image shows the colocalization of transplanted cell marker YFP and the neuronal marker NeuN, indicating neuronal differentiation and maturation of LM03-iPS-NPCS. B, C, NeuN and BrdU double-positive cells illustrate new neurons. C, Bar graph represents that the ischemic stroke was an insult and trigger inducing neurogenesis. Both cell transplantation and the cell/CTZ treatments further increased the number of newly formed neurons. (TZ showed a trend of greater effect than cell alone, although it was not statistically significant. ${ }^{*} p<0.05$ versus sham control (one-way ANOVA). ${ }^{\#} p<0.05$ versus stroke control (one-way ANOVA). $n=10-12$ per group. $\boldsymbol{D}, \boldsymbol{E}$, Angiogenesis was measured using the vessel marker Glut-1 colabeled with BrdU. $\boldsymbol{E}$, Bar graph represents that angiogenesis was induced after stroke, whereas both two treatments further increased the number of new vascular structures. ${ }^{*} p<0.05$ versus sham control (one-way ANOVA). ${ }^{\#} p<0.05$ versus stroke control (one-way ANOVA). $n=10-12$ per

ing and after light application (Fig. 10K). At the end of the $30 \mathrm{~min}$ recording after CTZ or light stimulation, the slope of fEPSPs was doubled compared with the baseline level (Fig. 10L). On the contrary, fEPSPs in control recordings with drug-free solution or low-frequency photostimulation were stable throughout the re- 
A

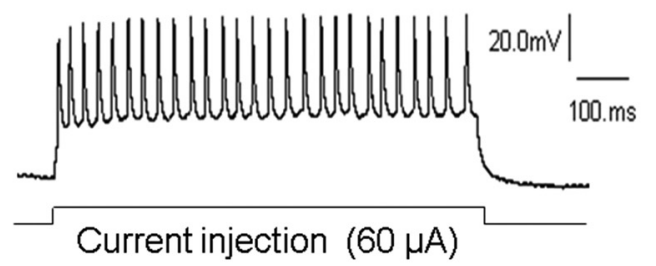

c

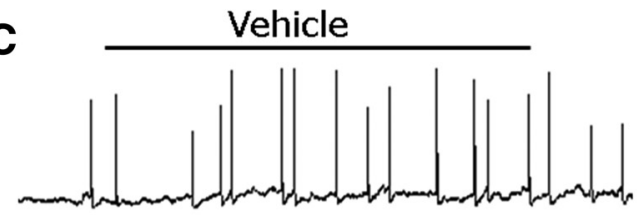

B
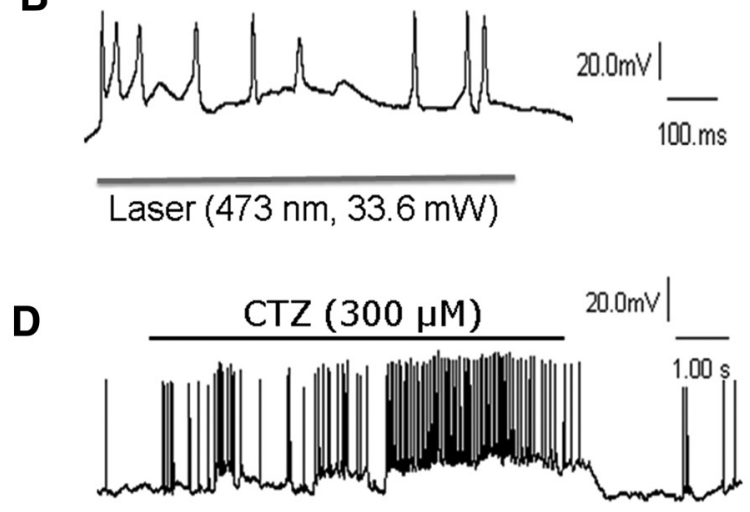
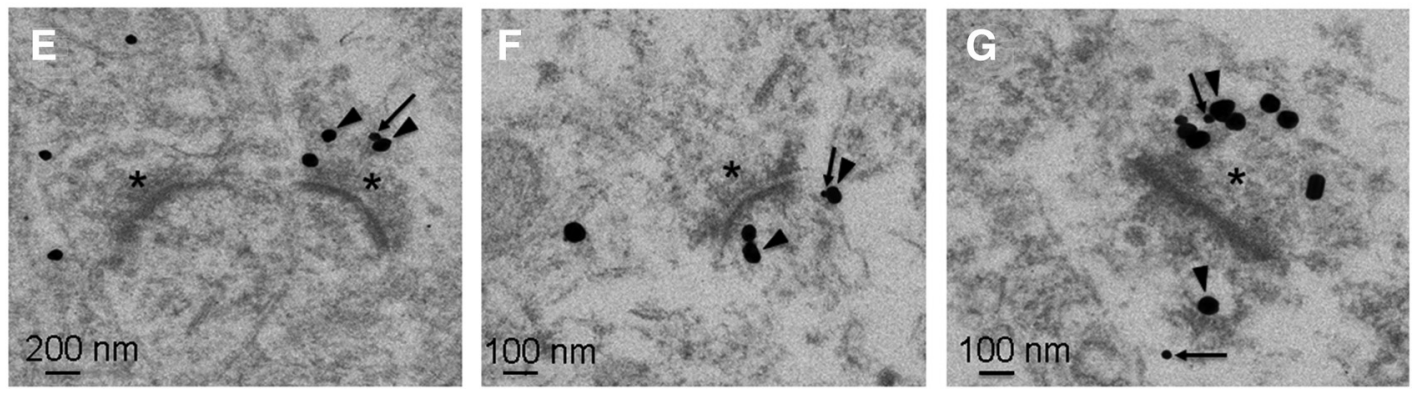

Figure 9. Regulation of action potential firing in LM03-iPS-NPC-derived neurons and formation of synapses. A, Whole-cell recording in a brain slice 3 weeks after infection with the LM03 lentivirus. Current injection via the recording electrode evoked action potentials in EYFP-positive cells. B, Blue laser light stimuli ( $473 \mathrm{~nm}, 33.6 \mathrm{~mW})$ induced membrane depolarization and action potential in EYFP-labeled neurons. $\boldsymbol{C}, \boldsymbol{D}$, Whole-cell recordings in brain slices expressing the LM03 protein demonstrate a marked increase in firing frequency upon application of CTZ (300 $\mu \mathrm{m}$ ) compared with vehicle controls. The firing frequency increased from $2.8 \pm 1.1 \mathrm{HZ}$ in control cells to $19.5 \pm 3.3 \mathrm{~Hz}$ upon the application of $\mathrm{CTZ}(t$ test, $p<0.05) ; n=5 . \boldsymbol{E}-\mathbf{G}, \mathrm{Immunoelectron}$ microscopy micrographs of synapses in the peri-infarct region $28 \mathrm{~d}$ after stroke (21 d after cell transplantation). The characteristic electron-dense structure postsynaptic density (an $\sim 30$-nm-thick dark band located between the presynaptic and postsynaptic neurons). (lusters of synaptic vesicles indicate presynapses ${ }^{*}$ ). Large black dot (arrowhead) labeled GFP/EYFP-positive neurons is derived from transplanted LM03-iPS-NPCS. Smaller black dot (arrow) reveals the expression of microtubules as a neuronal marker. $\boldsymbol{E}$, Micrograph represents two synapses, and the synapse on the right is formed between the transplanted cell labeled with black dots as a presynaptic neuron and a host neuron (no black dot) as the postsynaptic neuron. $F$, Synapse formed between a presynaptic host neuron and a transplanted postsynaptic neuron. G, Synapse likely formed between two transplanted cells because large and small black dots existed in both sides of the synapse. Representative of brain samples from 7 animals.

cording (Fig. 10G,J,K). These results verified that facilitated transmitter release and a synaptic LTP-like effect were induced by excitation of transplanted cells that had been conditioned by the activation of LMO3 channels. The involved neurons were glutamatergic since their synaptic events were completely blocked by glutamate receptor antagonists NBQX $(10 \mu \mathrm{M})$ and D-AP5 (5 $\mu \mathrm{M})$ (Fig. $10 \mathrm{~J}, \mathrm{~K})$. Thus, transplanted LMO3-iPS-NPCs differentiated into glutamatergic neurons and integrated into existing circuits within and between cortical column structures, leading to enforced intrabarrel and interbarrel connectivity and neuronal synaptic plasticity.

Intranasally delivered CTZ stimulation of grafted LMO3-iPSNPCs restored thalamocortical connections after stroke

To examine the thalamo-cortico-thalamic connectivity impaired after stroke, electrophysiological recordings were performed in vivo in the VPM nucleus of the thalamus to assess neuronal activities in the thalamo-cortico-thalamic pathway (Fig. 11A). One month after stroke, the single-unit recording detected neuronal activity in the VPM barreloid neurons (Fig. 11A-D), an indication of thalamo-cortico-thalamic connectivity involving afferent information from the brainstem and efferent signals from the barrel cortex (Temereanca and Simons, 2003). The frequency of this thalamo-cortico-thalamic activity was selectively increased by mechanical stimulation of contralateral whiskers, and this in- crease in firing rate was much reduced by stroke (Fig. $11 B, C)(\mathrm{L}$. Wei et al., 2004). In stroke mice of the combined treatment of LMO3-iPS-NPC plus CTZ, the firing rate of VPM neurons during whisker stimulation was protected (nonparametric MannWhitney's $U$ test; mean rank difference $=-11.05, p=0.0315$, $n=5-8$ per group) (Fig. $11 D$ ). This was not seen in the cell transplantation alone group, suggesting that CTZ stimulation of LMO3 in transplanted cells effectively restored the connectivity and propagation of neuronal signals along the whisker-thalamusbarrel cortex pathway. During the course of experimental procedures, no epileptic behavior/activity was observed in animals receiving LMO3-iPS-NPC transplantation and/or CTZ stimulation by eye surveillance or the MEA recording in brain slices.

Intranasally delivered CTZ stimulated grafted LMO3-iPSNPCs and promoted functional/behavioral recovery after stroke

One month after stroke, mice that received LMO3-iPS-NPCs responded to intranasal CTZ administration with increased whisker-touching behaviors (nonparametric Mann-Whitney test, $p=0.0437$ vs saline control, $n=8$ and 6 , respectively) (Fig. $12 A)$. In contrast, stroke mice received iPS-NPCs expressing the ChR2 protein or LMO3-D248A-iPS-NPCs showed no response to CTZ administrations ( $p=0.3056$ vs saline control, $n=8$ per group) (Fig. 12A). The CTZ triggered whisker-touching behavior 
A Baseline

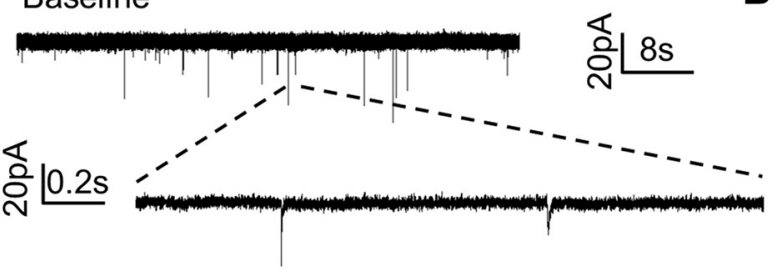

CTZ

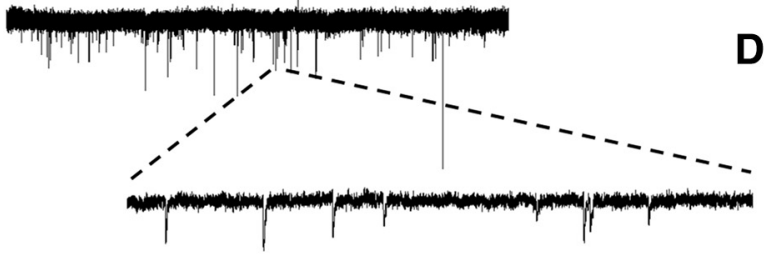

NBQX+AP5

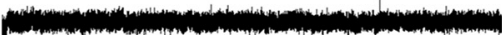

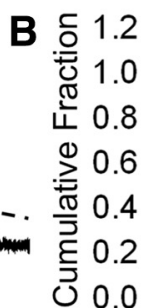

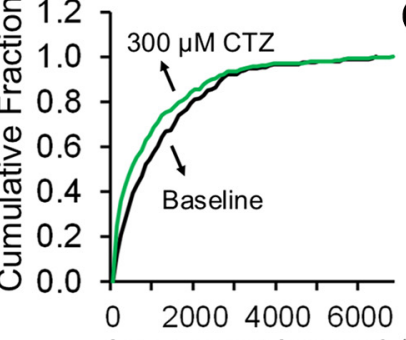

Inter-event Interval (m

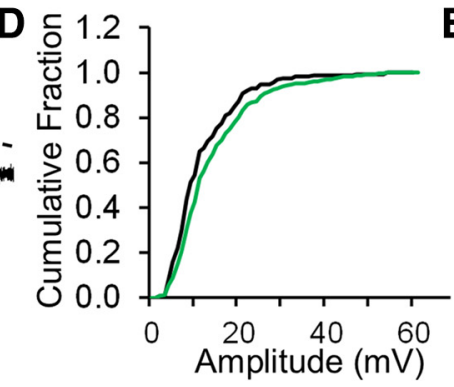

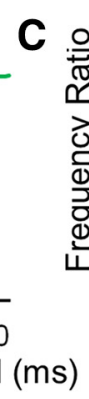

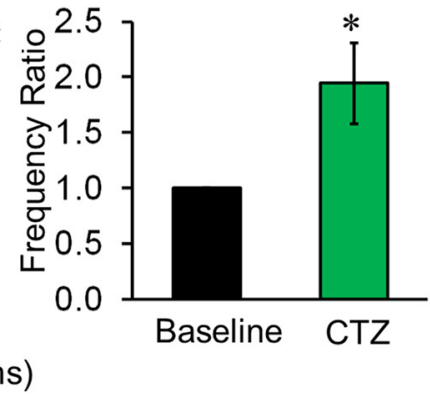

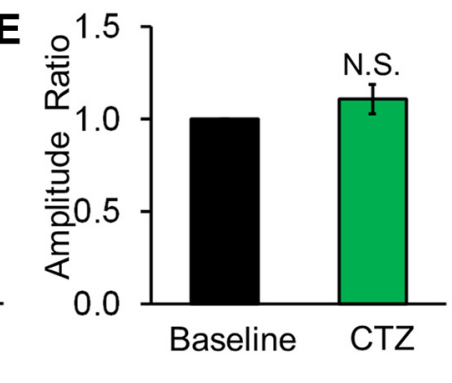
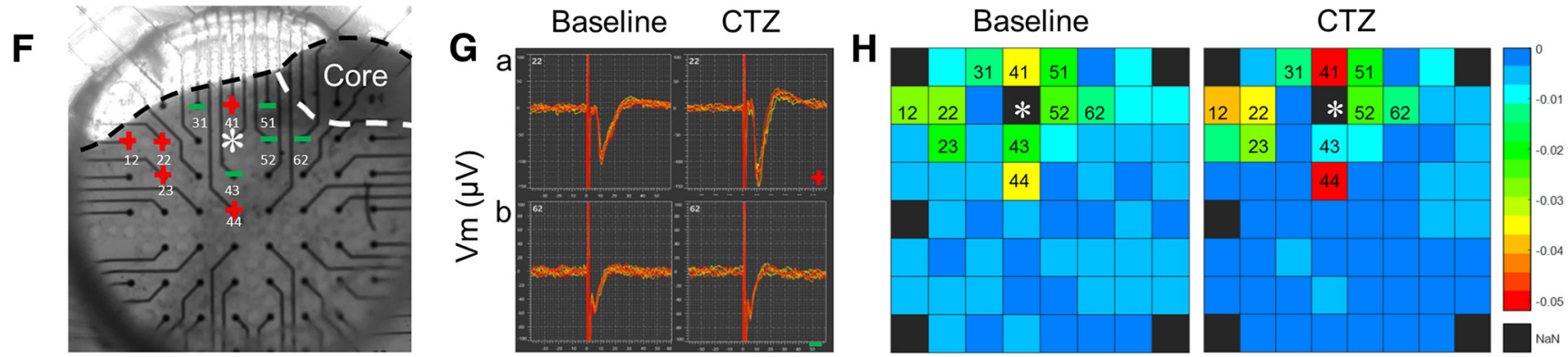

Time (ms)
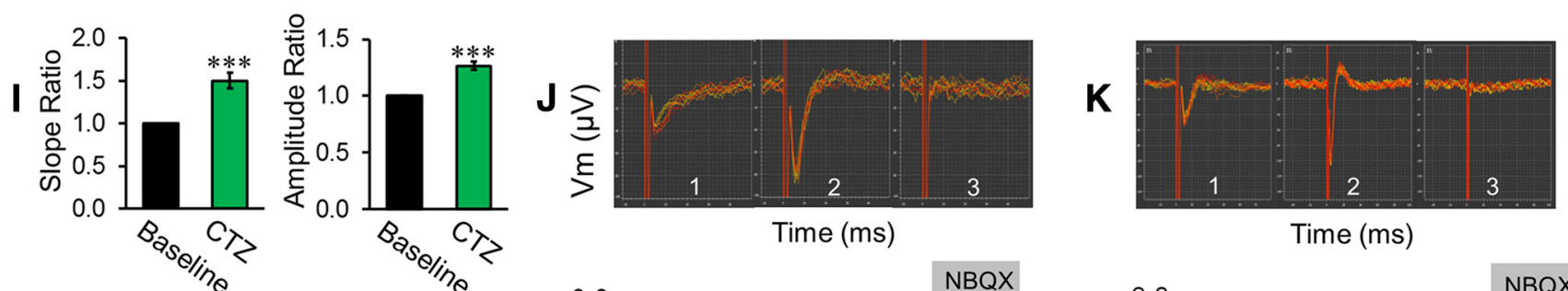

Time (ms)
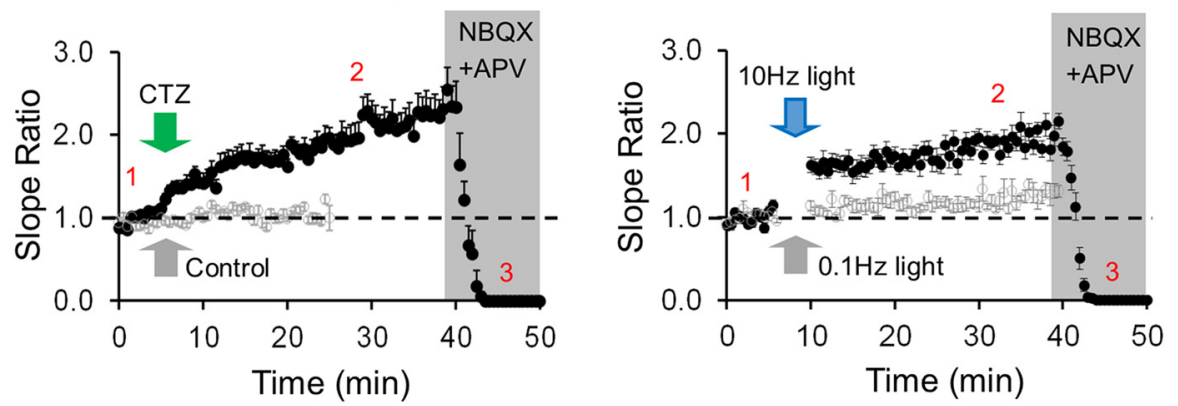

Figure 10. Neuronal circuit repair in the peri-infarct region of the barrel cortex. Stroke mice received LM03-iPS-NPCs at $7 \mathrm{~d}$ after stroke, followed by intranasal CTZ ( $2 \mathrm{mg} / \mathrm{kg}$ ) daily treatment for $14 \mathrm{~d}$. $\boldsymbol{A}-\boldsymbol{E}$, Three weeks after stroke, whole-cell voltage clamp was performed in brain slices to characterize the sEPSCs in endogenous neurons surrounding the fluorescence-positive LM03 cells. Exposure to $300 \mu \mathrm{M}$ CTZ in the bath solution significantly increased the frequency ofsEPSCs by $\sim 2$-fold, and no significant difference was found in the amplitude. The glutamate receptor antagonists NBQX $(10 \mu \mathrm{M})$ and D-AP5 $(5 \mu \mathrm{M})$ completely blocked the occurrence of sEPSCS. $n=5$ brain slices from 3 animals in each group. $F$, MEA in brain slices recorded the fEPSPs. The distance between two electrodes was $200 \mu \mathrm{m}$. Image represents the distribution of electrodes against the coronal brain section containing the ischemic core (white dotted line) of the barrel cortex and peri-infarct areas. Black dotted line outlines the edge of the slice. *The location of the electric stimulation electrode, which was $200-400 \mu \mathrm{m}$ away from the ischemic core. fEPSPs were triggered by electric pulse $( \pm 1500 \mathrm{mV}, 0.1 \mathrm{~ms}$, once every $30 \mathrm{~s}$ ) and were stable in control recordings. After stabilization of fEPSP baseline recordings for at least $5 \mathrm{~min}$, the brain slice was exposed to (TZ (100 $\mu \mathrm{m}$ ) for $5 \mathrm{~min}$ or light $(473 \mathrm{~mm}, 10 \mathrm{~Hz}$ for $10 \mathrm{~s}$, separated by 10 sintervals) for $4 \mathrm{~min}$. fEPSPs were continuously monitored in 58 electrodes (minus one stimulation electrode and one reference electrode from total 60). Eighteen of 58 locations detected fEPSPS. Red plus sign represents reaction sites where fEPSPs were markedly upregulated by CTZ application. Green sign represents no-response sites (see corresponding heat map in $\boldsymbol{H}$ ). $\mathbf{G}$, Examples of fEPSP traces during (TZ exposure. The initial up and down sharp spikes were the stimulation artifacts, followed by the fEPSP response mediated by synaptic transmission. $\boldsymbol{H}$, The fEPSP heat map shows the locations of changes of fEPSPs with CTZ exposure. The cortical regions showed strongest rEPSP enhancements (Figure legend continues.) 
A

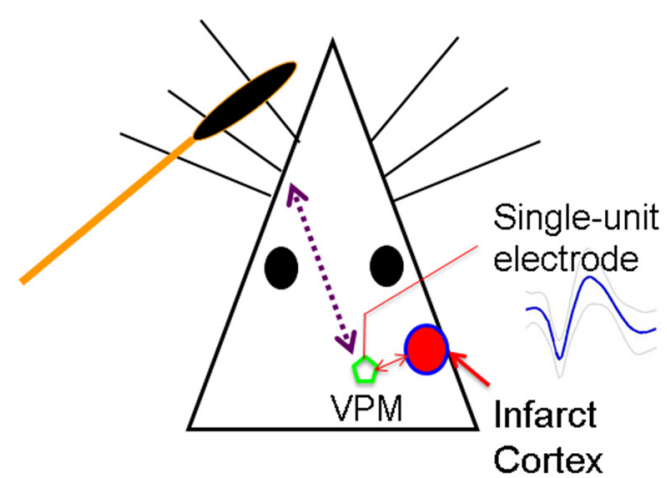

C
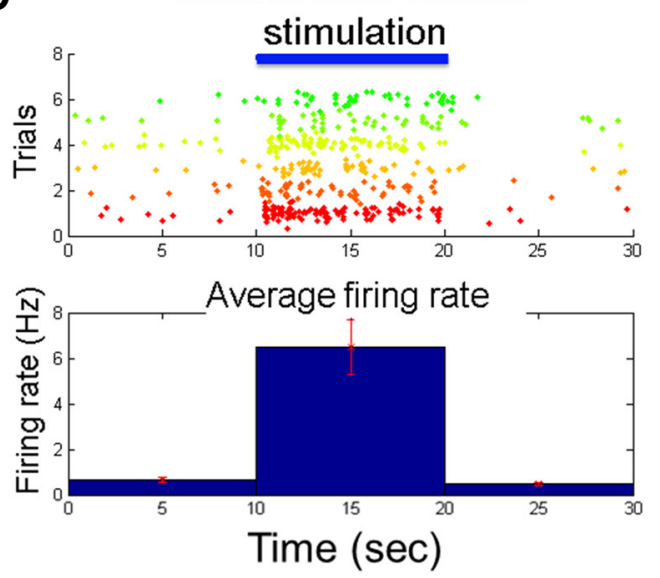

B
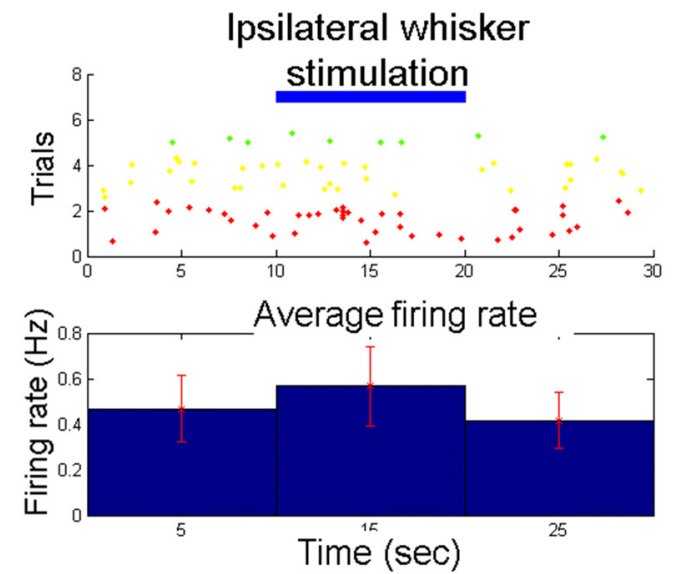

D

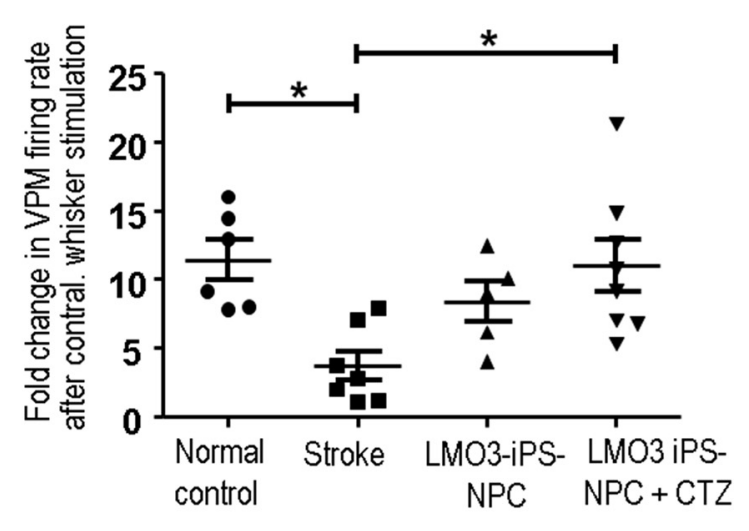

Figure 11. LM03-iPS-NPC transplantation and CTZ treatment restored functional connections of the thalamo-cortico-thalamic pathway after stroke. The neuronal activity in the VPM that relays the afferent and efferent signals in the thalamocortical pathway was recorded using extracellular recordings 1 month after stroke ( 3 weeks after cell transplantation). $\boldsymbol{A}$, Schematic diagram showing the neuronal connection and experimental setup. The VPM ipsilateral to focal ischemic stroke was recorded during whisker stimulation. $\boldsymbol{B}$, Recording in a naive mouse. Top, Raster plot showing the single-unit response in the VPM to corresponding whisker stimulation. Colors represent different stimulation trials. Bottom, The average single-unit firing rate across all trials did not significantly change during ipsilateral whisker stimulation, which is a negative stimulation control in this test. C, Recording in a naive mouse. Top, Raster plot showing the single-unit response in VPM to contralateral whisker stimulation. Bottom, The average firing rate of neurons in VPM was noticeably increased during contralateral whisker stimulation. $\boldsymbol{D}$, The fold change in average firing rates of ipsilateral VPM neurons during contralateral whisker stimulation. Compared with naive animals, stroke animals showed weak response during whisker stimulation, whereas stroke animals receiving the combined cell/CTZ treatment (Stroke $+\mathrm{LMO3}+$ (TZ) significantly restored the neuronal response. ${ }^{*} p<0.05 . n=5$ in control and 8 in experimental groups.

$\leftarrow$

(Figure legend continued.) in responding to CTZ were sites 41 and 44 , which were located in the same cortical column judged from the brain slice orientation in $\boldsymbol{F}$. Several responding sites were $400-600 \mu \mathrm{m}$ away from the stimulation site $\left(^{*}\right)$, implicating neurons in a different cortical column. For example, fEPSPs in sites 12 and 22 were noticeably facilitated by CTZ, possibly achieved by interbarrel connection and regulation. In multiple locations, there were downregulations of fEPSPs shown in the color change from light blue to dark blue. Inhibitory interneurons might regulate these sites. $I$, The ratio of increased slope and amplitude of fEPSPS before and during the (TZ exposure. ${ }^{* *} p<0.001$ ( $t$ test). $n=7$ slices from 4 animals. J, $\boldsymbol{K}$, Representative fEPSP traces at different time points before and after CTZ or light stimulation or in control recordings. Dot graphs underneath traces in $\boldsymbol{J}$ and $\boldsymbol{K}$ represent the time- and stimulation-dependent LTP-like enhancements of fEPSPs. 1, 2, and 3 indicate the recorded traces and their corresponding locations in the dot graphs. Progressive enhancements of fEPSPS developed, even after the termination of CTZ or light stimulation for at least $30 \mathrm{~min}$. These events were blocked by glutamate receptor antagonists NBQX $(10 \mu \mathrm{M})$ and D-AP5 $(5 \mu \mathrm{M})$. Control recordings were performed with drug-free solution or low-frequency light stimuli, showing no significant change of fEPSPs. $L$, Bar graph represents the increased ratio of fEPSPs at $30 \mathrm{~min}$ after CTZ or light stimulation, normalized against the baseline level ( $F=32.68663)$. ${ }^{* * *} p<0.001$ (one-way ANOVA). $n=7$ slices from 4 animals in (TZ and light groups, respectively. $n=15$ in CTZ-free control and $n=5$ in low-frequency light control. of these mice was markedly different compared with stroke mice in the LMO3-iPS-NPCs group ( $p=0.0119$ ) (Fig. 12A). Similar results of the whisker-touching behavior were obtained $21 \mathrm{~d}$ after stroke in both male and female mice receiving the LMO3-iPSNPCs/CTZ treatment (Fig. 12B).

In the adhesive removal test, stroke animals took a significantly longer time to detect (contact) and remove the adhesive stickers attached to the forepaw of the affected side (Fig. 12C,D). Cell transplantation alone significantly improved the performance in removing the adhesives tested 14 and $21 \mathrm{~d}$ after stroke (nonparametric Kruskal-Wallis test; $14 \mathrm{~d}: p=0.038 ; 21 \mathrm{~d}: p=0.0095)$. The combination of cell transplantation and CTZ treatment (Stroke+LMO3$i P S+C T Z)$ improved the sensorimotor function in both detecting and removing the adhesives ( $14 \mathrm{~d}$ contact: $p=0.0054$; $14 \mathrm{~d}$ removal: $p<0.0001 ; 21$ d contact: $p=0.0692 ; 21$ d removal: $p<0.0001$; Stroke vs Stroke+LMO3-iPS+CTZ) (Fig. 12C,D). In negative control experiments, stroke mice received vehicle or CTZ treatment alone showed no difference in their performance (Fig. 12E,F).

We examined coordinated motor function of the reach-tograsp test that is more sensitive and clinically relevant (Marques and Olsson, 2010). In sham control and stroke animals, the suc- 
A

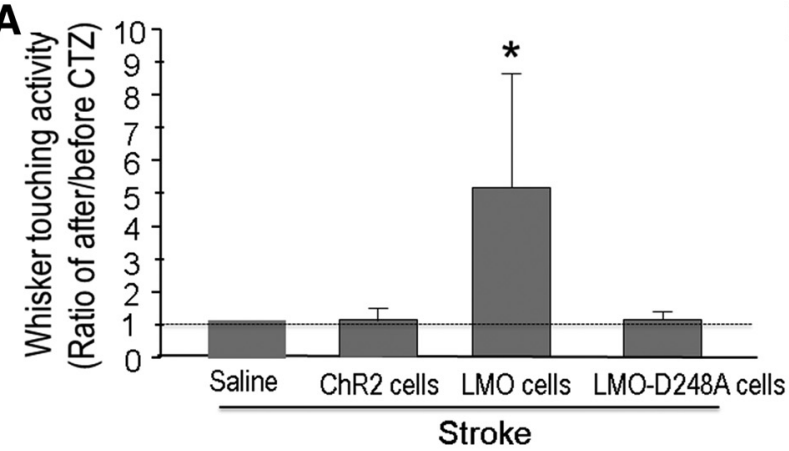

C

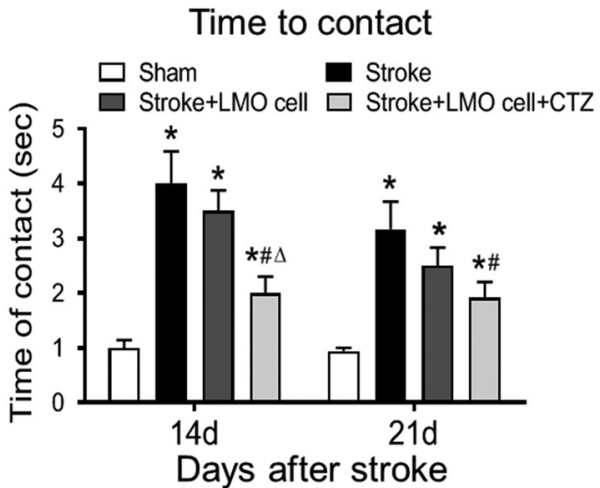

E

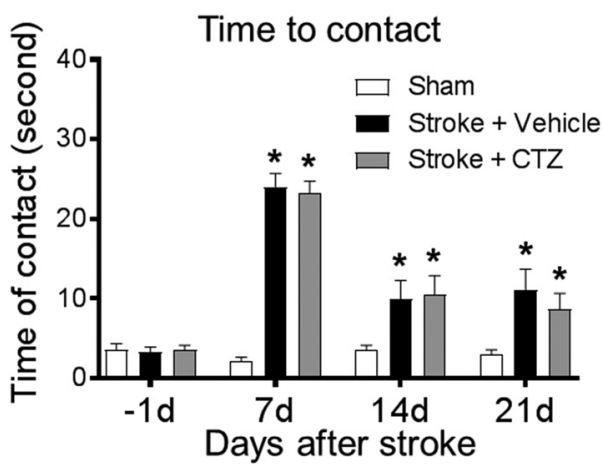

G

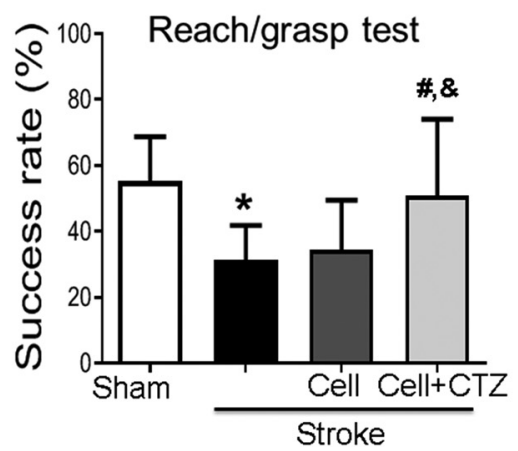

B

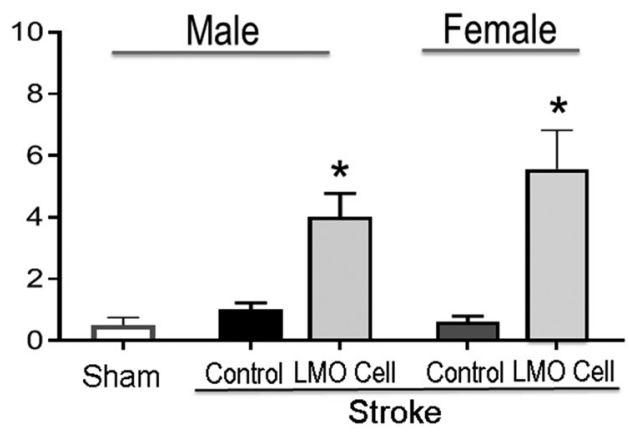

D Time of removal

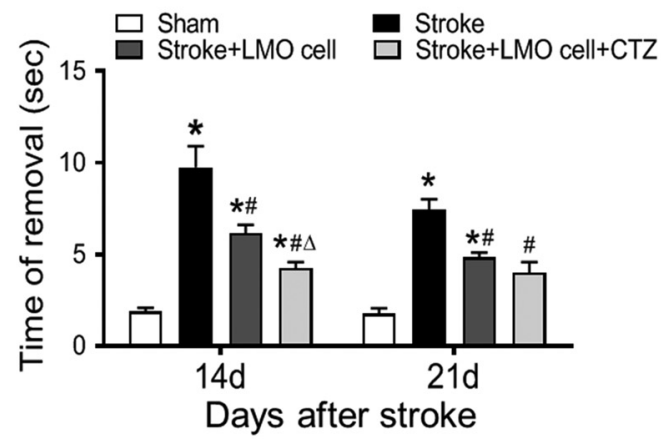

F

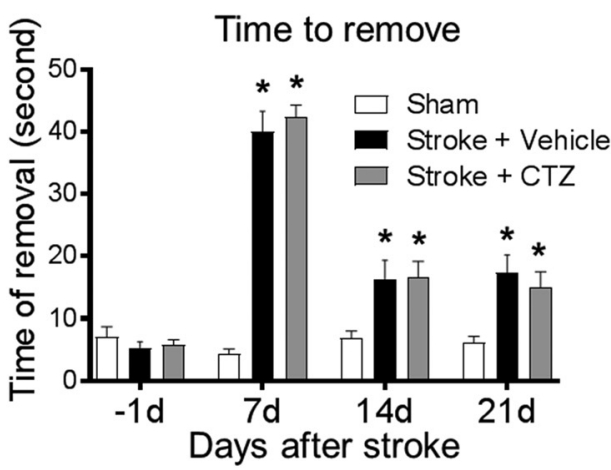

H

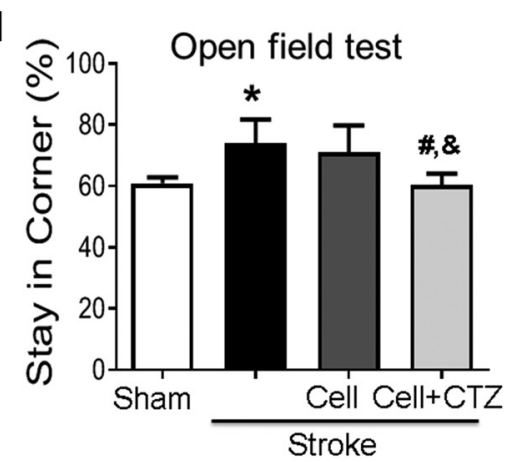

Figure 12. LM03 activation improved functional recovery after ischemic stroke. $\boldsymbol{A}$, One month after stroke, animals in different groups were examined for the whisker-touching behavior triggered by intranasally administered CTZ, which is a specific acute examination of the functional integrity of the whisker-thalamus-barrel cortex neuronal pathway. CTZ (2 mg/kg) was intranasally delivered, and the time of the animals spent in touching their whiskers using forepaws was counted. The count was started 5 min after the administration of CTZ and ended 5 min later to avoid counting the animal reaction to a possible local skin assault. Only the animals that received LM03-iPS-NPC transplantation responded with increased whisker-touching behavior. Stroke mice received iPS-NPCs expressing the optogenetic gene ChR2, which does not bind to CTZ or the mutant LM03-D248A protein; both failed to show any response to CTZ administration. ${ }^{*} p<0.05$ versus all groups (nonparametric Mann-Whitney test). ${ }^{\#} p=0.0119$ versus LM03 group (nonparametric Mann-Whitney test). $n=6-8$ per group. For detailed values in statistical analysis, see text. $\boldsymbol{B}$, The responsive whisker-touching behavior in adult male and female mice of sham control and after stroke. Sham and stroke control mice ( $28 \mathrm{~d}$ after stroke) show no whisker-touching behavior after the CTZ delivery. Stroke mice (male and female) receiving LM0 cells plus the daily CTZ treatment showed increased whisker-touching activities in responding to the acute application of CTZ. $n=16$ for sham control group. $n=13$ for stroke controls of male and female groups. $n=18$ and $n=16$ for stroke plus LMO cells and daily CTZ treatments of male and female, respectively. $F_{(4,71)}=9.944$. ${ }^{*} p<0.05$ compared with stroke vehicle controls (male or female). C, D, The sensorimotor function of animals in experimental groups was evaluated using adhesive removal test at 14 and $21 \mathrm{~d}$ after stroke. Stroke animals took a longer time to detect and remove the sticky dot on their left paw compared with sham animals. Stroke animals receiving the (Figure legend continues.) 
cess rate of fetching the food pellet was $60 \%$ and $30 \%$, respectively. Cell transplantation showed a trend of improving the success rate, whereas cell transplantation combined with CTZ treatment significantly improved the motor coordination to the normal level (one-way ANOVA with Bonferroni's correction; $p=0.0013$ vs stroke control; $p=0.032$ vs cell only group; no difference from sham controls, $p=0.0865$ ) (Fig. 12G). In the open field test of anxiety behaviors, animals with stroke had the preference of staying in corners, suggesting increased anxiety and stress (Fig. 12H). This behavior was corrected by the cell/CTZ combination therapy so animals spent less time in the corner area ( $p=0.0013$ vs stroke controls; $p=0.1008$ vs sham controls) (Fig. $12 \mathrm{H})$.

Functional recovery after stroke in male, female, young adult, and aged mice

The above in vivo experiments were performed in young adult male mice. Next, we examined gender and age factors in responding to the optochemogenetics therapy. The corner test is a widely used functional assessment for unilateral sensorimotor cortical damage (Zhang et al., 2002; Choi et al., 2012). Normal mice make about equal left and right turns in their exploratory turning behavior. After the ischemic insult to the right sensorimotor cortex, both male and female animals showed biased turns consistent with the side of their brain damage (Fig. $13 A, B$ ). In male stroke mice of young adult ( 2 months old) receiving no cell transplantation, the CTZ intranasal multiday deliveries showed no effect of correcting this functional deficit, whereas LMO3 cells plus CTZ daily treatment restored the functional behavior to the normal level (one-way ANOVA and Bonferroni correction, $p=0.010$ vs stroke control, $p=0.0386$ vs cell only group) (Fig. $13 A$ ). In young female stroke mice, CTZ stimulation appeared to have some benefits, but only the combined cell/CTZ treatment significantly improved the behavior back to normal ( $p=0.038$ vs stroke control, $p=0.045$ vs cell only) (Fig. 13A). The same functional benefits of LMO3 cell plus CTZ treatment were verified in aged male and female stroke mice (Fig. 13B; for statistics, see the figure legend).

$\leftarrow$

(Figure legend continued.) cell/CTZ combined treatment performed significantly faster compared with stroke control and stroke plus cell groups. ${ }^{*} p<0.05$ versus sham (nonparametric Kruskal-Wallis test). ${ }^{\#} p<0.05$ versus stroke alone (nonparametric Kruskal-Wallis test). ${ }^{\Delta} p<$ 0.05 versus stroke plus LM03-iPS-NPC transplantation group (nonparametric Kruskal-Wallis test). For detailed analysis values, see text. $n=12-16$ per group. $\boldsymbol{E}, \boldsymbol{F}$, The adhesive removal test was repeated in stroke animals receiving no cell transplantation. The same CTZ daily treatment in those animals showed no benefit in this negative control experiment. $n=8$ per group. Performed at 7, 14, and $21 \mathrm{~d}$ after stroke, the two stroke groups with vehicle or CTZ alone performed similarly, verifying that CTZ by itself did not have any functional benefit. ${ }^{*} p<0.05$ versus sham controls (one-way ANOVA). $p>0.05$ between vehicle and CTZ groups (one-way ANOVA). $\mathbf{G}$, The reach and grasp test examined the coordinative motor function of accurate control of reaching and grasping food pellets placed $1.5 \mathrm{~cm}$ away from the animal. Stroke significantly reduced the success rate of the activity. Cell transplantation alone did not improve this challenging behavior, whereas cell/CTZ combined treatment brought the performance back to the normal level. $n=14$ for sham controls. $n=10$ for stroke controls. $n=12$ for stroke plus LMO cells. $n=11$ for stroke plus LMO cell/CTZ group. $F_{(3,40)}=6.0 .{ }^{*} p<0.05$ versus sham control (one-way ANOVA). ${ }^{\#} p<0.05$ versus stroke control (one-way ANOVA). ${ }^{\&} p<0.05$ versus cell alone (one-way ANOVA). $\boldsymbol{H}$, The open field test was used to detect anxiety-like behavior that chronically develops in stroke models. Stroke animals exhibited enhanced anxiety behavior of staying in the corner. Again, the LMO cell/CTZ combined treatment reduced the anxiety level back to normal. $n=6$ for sham group. $n=18$ for stroke controls. $n=12$ for stroke plus LMO cells. $n=10$ for LMO cell/CTZ group. $F_{(3,34)}=5.0$. ${ }^{*} p<0.05$ versus sham control (one-way ANOVA). ${ }^{\#} p<0.05$ versus stroke control (one-way ANOVA). ${ }^{{ }^{*}} p<0.05$ versus cell alone (one-way ANOVA).
A unilateral injury to the motor cortex results in an asymmetry in the forelimb used for support during rearing, which can be measured using the cylinder test (Lee et al., 2016). Two weeks after stroke, the focal cerebral ischemia in male young adult mice induced significantly reduced use of the affected forelimb; CTZ alone did not show any effect on the deficit $(p>0.999$ vs stroke control) (Fig. 13C). In female animals, the motor deficit was obvious after stroke; CTZ alone appeared to induce some improvement compared with stroke controls $(p=0.021$ vs stroke control). The LMO3 cell transplantation plus CTZ group showed a complete improvement in the forelimb function ( $p=0.0146 \mathrm{vs}$ stroke control); the effect was significantly better compared with the CTZ group ( $p=0.008$ vs cell alone) (Fig. $13 C$ ). The same experiments were repeated in aged (18-month-old) animals to understand whether the therapeutic benefit was age dependent. Again, both male and female mice showed reduced use of their affected limbs. Mice in the CTZ alone group did not have significant improvement, whereas the LMO3-cell plus CTZ treatment partly recovered the motor deficit in aged male mice (Fig. 13D). In aged female mice, the combined treatment noticeably promoted the use of affected forelimb, whereas CTZ alone had no benefit (Fig. 13D; for statistics, see the figure legend).

\section{Discussion}

The present investigation created a stable iPS cell line expressing the novel optochemogenetic probe LMO3 of a bioluminescent luciferase and an excitatory opsin. Membrane depolarization of cells expressing LMO3 could be induced by either physical photostimulation or bioluminescence with the luciferase substrate, CTZ. This unique feature allows for optochemogenetic controls of iPS-derived cells in vitro as well as after transplantation into the brain via intranasally delivered CTZ. Stimulations of LMO3-iPSNPCs created an enriched microenvironment of increased growth/trophic factors, leading to enhanced neuronal differentiation and neural network repair. In mice receiving LMO3-iPSNPC transplantation after stroke, the CTZ stimulation of these cells resulted in activity-dependent benefits, including the establishment of synaptic connections, increased axonal outgrowth and myelination, formation of functional neuronal pathways, augmented neuronal plasticity, and improvements of functional/ behavioral recovery after stroke. The MEA recording in brain slices and in vivo single-unit recordings affords novel evidence for reestablishments of cortical connections and the thalamocortico-thalamic pathway after stroke. The neuroplasticity of LTP-like modulation endorsed by the cell/CTZ therapy and acute CTZ stimulation implies an underlying mechanism for improved sensorimotor and behavioral functions after stroke as proposed in a working model of this study (Fig. 14).

Luminopsins possess unique features. The greatest advantage is the activation of the opsin by bioluminescence upon catalyzing its substrate. It is thus able to circumvent the invasive and bulky hardware requirements (optical fiber and light source) in optogenetics (Berglund et al., 2013, 2016a, b; Tung et al., 2015). Furthermore, the pharmacological approach provides neural excitation of transplanted cells in larger brain regions. This advantage is particularly important with the fact that transplanted cells are mobile and capable of migrating long distances (Kelly et al., 2004). Luminopsins retain the sensitivity to physical light, useful for interrogation of functional integration of transplanted cells (Boyden et al., 2005). Up to now, the only optochemogenetics report was a study of controlling "caged" tamoxifen analogs in gene expression ( $\mathrm{Lu}$ et al., 2012). The term "optochemogenetics" is used in our investigation to distin- 

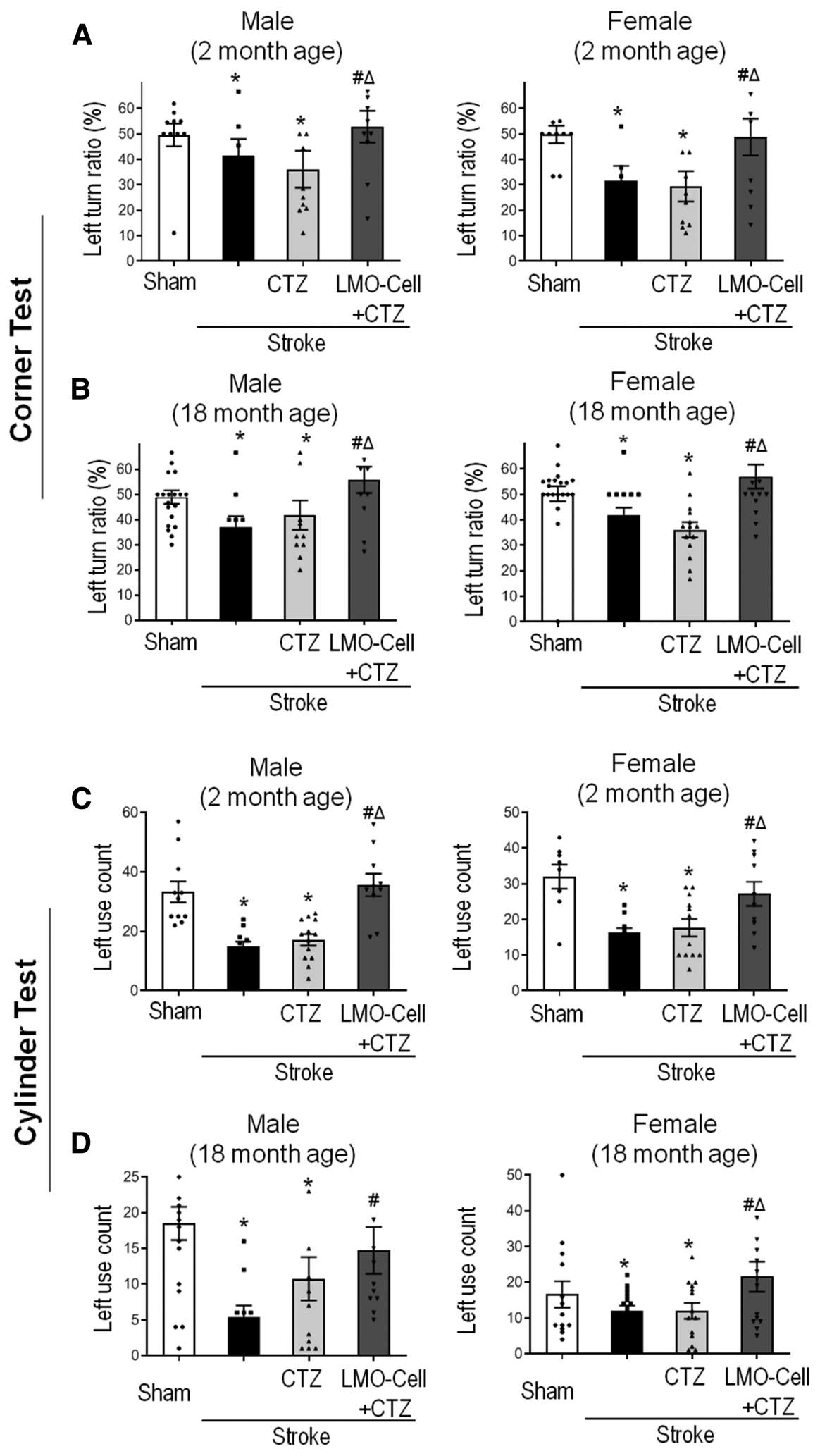

guish from the conventional optogenetics as well as from chemogenetics, which often refers to the designer receptors exclusively activated by designer drugs (DREADDs) (Chen et al., 2016). The mechanism of action of DREADDs is different from luminopsin-induced activation. DREADDs use G-protein-coupled receptor signaling pathways that have widespread effects. The optochemogenetic, on the other hand, provides a unique tool and potential clinical treatments with highly selective control of neuronal cells. The present investigation is the first successful attempt to develop optochemogenetics tools in iPS transplantation therapy for the treatment of a brain disorder.

In our in vivo experiments, the $\mathrm{LMO} 3$ activation was achieved by the noninvasive intranasal delivery of CTZ. The nasalbrain route has been used for delivering neuropeptides, trophic factors, and stem cells to the brain (Lioutas et al., 2015; Z. Z. Wei et al., 2015). Because of the noninvasive nature and the feasibility of repeated administrations, intranasal drug delivery reduces risks associated with exposures to anesthesia, surgical procedures, inflammation/infection, and stress. So far, intranasal delivery has been used clinically for a

and aged mice (for young male: $p=0.010$ vs stroke controls, $p=0.038$ vs stroke plus CTZ; for young female: $p=0.038$ vs stroke controls, $p=0.045$ vs stroke plus $\mathrm{CTZ}$; for aged male: $p=0.031$ vs stroke controls, $p=0.039$ vs stroke plus CTZ; for aged female: $p>0.999$ vs stroke controls, $p>0.999$ vs stroke plus (TZ; but $p>0.999$ vs sham control). $n=10$ for each group, except male stroke only control $(n=14)$. One-way ANOVA followed by Bonferroni correction: young male group: $F_{(3,40)}=1.309$; young female group: $F_{(3,36)}=3.520$; aged male group: $F_{(3,48)}=3.164$; aged female group: $F_{(3,62)}=$ 6.432. ${ }^{*} p<0.05$ versus sham. ${ }^{\#} p<0.05$ versus stroke control. ${ }_{p}<0.05$ versus CTZ alone. $C, D$, The cylinder test detected the motor deficit of affected limb of stroke mice. Stroke induced much less use of the affected limb in 2-month-old male and female mice. CTZ showed no effect in male mice ( $p>0.999$ vs stroke controls) but some improvement in female mice ( $p=0.021$ vs stroke controls). Stroke mice received LMO-3 cells and CTZ treatment performed normally as shame controls (male: $p=0.016$ vs stroke controls; female: 0.015 vs stroke controls), which was significantly better than CTZalone (male: $p=0.033$ vs stroke plus CTZ; female: 0.008 vs stroke plus (TZ). In aged mice of 18-month-old mice, CTZ or cell plus CTZ showed variable results, whereas the combination treatment promoted the use of the affected limb in aged female mice (aged male: $p>0.999$ vs stroke controls, $p>$ 0.999 vs stroke plus (TZ; aged female: $p=0.049$ vs stroke controls, $p=0.014$ vs stroke plus (TZ). One-way ANOVA followed by Bonferroni correction: young male: $F_{(3,41)}=14.67$; young female: $F_{(3,36)}=7.311$; aged male: $F_{(3,47)}=4.432$; aged female: $F_{(3,54)}=2.383 . n=11$ for sham and stroke control groups. $n=13$ for stroke with CTZ alone group. $n=$ 10 for stroke plus LMO-cells and CTZ. ${ }^{*} p<0.05$ versus sham. ${ }^{\#} p<0.05$ versus stroke control. ${ }^{\Delta} p<0.05$ versus CTZ alone. 


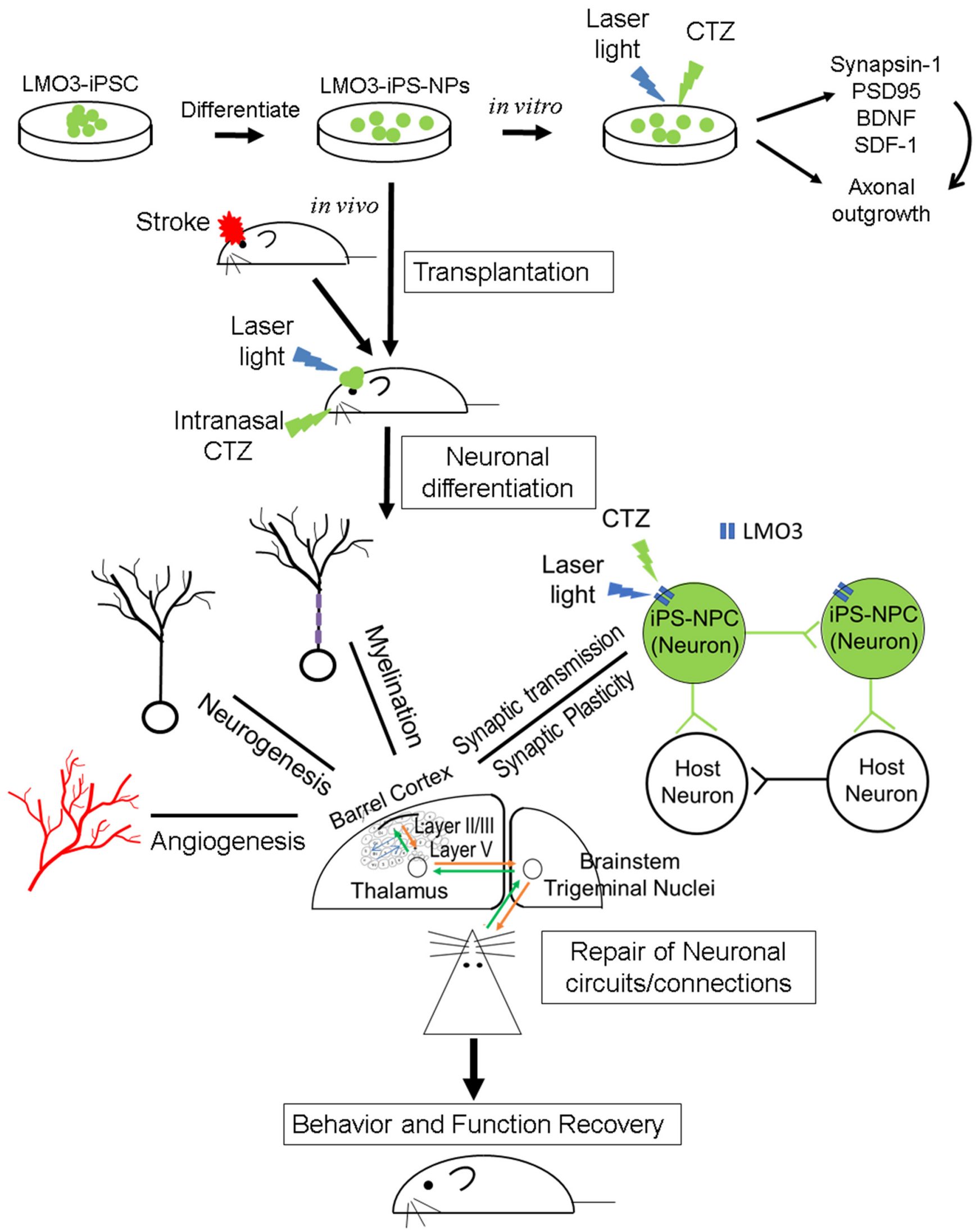

Figure 14. Illustration of the mechanisms and benefits of optochemogenetics stem cell therapy for ischemic stroke. Graph represents the experimental design in the investigation. It also outlines the hypothetical mechanisms and main therapeutic benefits induced by optochemogenetic stem cell therapy. 
variety of brain disorders, such as epilepsy and neurodegenerative diseases (Freiherr et al., 2013; Tayebati et al., 2013; Novak et al., 2014; Spetter and Hallschmid, 2015).

Direct shining of laser light could open ChR2 or LMO3 channels within millisecond ranges, whereas CTZ application activates the LMO3 channel in cultured cells in seconds and even minutes after in vivo administration. While millisecond resolution is important for correlating stimulus with fast response, the chemogenetic paradigm in a slow pace is better suited for a regenerative treatment. The LMO3 protein provides the capabilities for the cells to be activated either in a way mimicking neuronal activities of fast activation or manipulations of the channel/cell in clinical treatments. The greater sensitivity of VChR1 to blue light shows higher coupling efficiency with GLuc and cyan bioluminescence, evoking more photocurrents compared with the same luciferase paired with ChR2 (Berglund et al., 2013; Berglund et al., 2016b). Using the cell line we engineered, activation of grafted iPS-NPCs shows significant synergistic benefits in neuronal differentiation and regenerative activities.

While optogenetic and chemogenetic activations possess multiple differences, the ultimate physiological effects converge on the same signaling pathways. $\mathrm{Ca}^{2+}$ imaging showed increased intracellular $\mathrm{Ca}^{2+}$ following $\mathrm{LMO} 3$ activation. $\mathrm{Ca}^{2+}$ can activate a series of $\mathrm{Ca}^{2+}$-dependent molecules, such as CaMKII, cAMP, and protein kinase $\mathrm{A}$, and trigger the expression and release of prosurvival/proregenerative genes, such as BDNF and NGF (Lonze and Ginty, 2002; Park and Poo, 2013), which shows beneficial paracrine and synaptogenesis effects (Park and Poo, 2013). $\mathrm{BDNF}$ is an activity-dependent factor that promotes axonal sprouting and extension (Mamounas et al., 2000). Stimulation through LMO3 upregulated presynaptic and postsynaptic markers, synapsin- 1 and PSD95, suggesting the formation and stabilization of new synaptic contacts. Our electrophysiological recordings revealed robust synaptic activities in differentiated cells, indicating an activity-dependent maturation and synaptogenesis of iPS-derived neurons.

In the whisker-barrel cortex pathway, sensory signals are sent from the contralateral vibrissae to the primary somatosensory barrel cortex (S1) through the brainstem and the thalamus, which is in turn routed to the primary motor (M1) cortex to regulate whisker movements (Simons and Woolsey, 1979; Petersen, 2007). The tested stroke model allows for evaluation of circuit damage and repair through multiple approaches, including morphological, electrophysiological alterations, sensorimotor deficits determined by the adhesive removal task, and whisker-touching behaviors. Following focal injury in the barrel cortex, the reverberating secondary effects leads to remote disruption of thalamocortical activity (L. Wei et al., 1995; Mohamad et al., 2013; Paz et al., 2013; Fornito et al., 2015) and even retrograde neuronal degeneration of neurons in the VPM nucleus (L. Wei et al., 2004). Compared with naive animals, neuronal firing induced by whisker stimulation in the VPM ipsilateral to the stroke site showed diminished responses. This neurophysiological deficit was significantly ameliorated by the combined cell/ CTZ therapy, suggesting a novel cell-based rehabilitation strategy, particularly for restoration of damaged neuronal connectivity. Overall, the present investigation supports and successfully demonstrates the importance of activity in the integrity and functional repair of neuronal connections in sensorimotor recovery after brain injury (Alawieh et al., 2017).

We also addressed gender and age factors in the optochemogenetics therapy. Our data show that iPS-NPC transplantation and the combined cell/CTZ treatment are effective in most measurements of functional tests, although some beneficial effects may be less robust in aged male animals. Our rigorous control experiments in vitro and in animals provide compelling evidence that it is the selective LMO3 activation in iPS-NPCs responsible for the observed activities and benefits. Interestingly, in a few functional assessments, female animals seemed to show more or less response to CTZ alone (statistically significant in the corner test and cylinder test of young female mice). The observation needs to be verified in additional experiments of more functional tests; if it can be confirmed as a persistent phenomenon, a possible sex difference and underlying mechanism should be delineated.

It is important to achieve optimal functional recovery after stroke. To verify this issue, we examined functions that are essential and meaningful for daily activities of stroke patients. In these subacute and chronic assessments, the functionality of stroke animals recovered to normal levels after the cell/CTZ combinatory treatment. Clinical practice shows that even slight functional improvements, such as regaining movement of the palm/finger(s) or slow walking ability, can greatly improve the life quality of stroke patients. Accordingly, the minimal clinically important difference standard indicates that even $10 \%$ improvement in movement control can improve quality of life for patients with upper or lower limb impairments (Page, 2014; Pandian et al., 2016). In this regard, the functional recovery demonstrated in both genders and different ages is promising and of clinical significance.

In conclusion, the novel optochemogenetics approach provides a translational solution to take the advantage of selective activation of transplanted cells in a clinically feasible way to enhance regeneration, neural network repair, and functional recovery after stroke.

\section{References}

Alawieh A, Tomlinson S, Adkins D, Kautz S, Feng W (2017) Preclinical and clinical evidence on ipsilateral corticospinal projections: implication for motor recovery. Transl Stroke Res 8:529-540.

Bain G, Kitchens D, Yao M, Huettner JE, Gottlieb DI (1995) Embryonic stem cells express neuronal properties in vitro. Dev Biol 168:342-357.

Bergey GK, Fitzgerald SC, Schrier BK, Nelson PG (1981) Neuronal maturation in mammalian cell culture is dependent on spontaneous electrical activity. Brain Res 207:49-58.

Berglund K, Birkner E, Augustine GJ, Hochgeschwender U (2013) Lightemitting channelrhodopsins for combined optogenetic and chemicalgenetic control of neurons. PLoS One 8:e59759.

Berglund K, Tung JK, Higashikubo B, Gross RE, Moore CI, Hochgeschwender U (2016a) Combined optogenetic and chemogenetic control of neurons. Methods Mol Biol 1408:207-225.

Berglund K, Clissold K, Li HE, Wen L, Park SY, Gleixner J, Klein ME, Lu D, Barter JW, Rossi MA, Augustine GJ, Yin HH, Hochgeschwender U (2016b) Luminopsins integrate opto- and chemogenetics by using physical and biological light sources for opsin activation. Proc Natl Acad Sci U S A 113:E358-E367.

Bibel M, Richter J, Lacroix E, Barde YA (2007) Generation of a defined and uniform population of CNS progenitors and neurons from mouse embryonic stem cells. Nat Protoc 2:1034-1043.

Boissart C, Poulet A, Georges P, Darville H, Julita E, Delorme R, Bourgeron T, Peschanski M, Benchoua A (2013) Differentiation from human pluripotent stem cells of cortical neurons of the superficial layers amenable to psychiatric disease modeling and high-throughput drug screening. Transl Psychiatry 3:e294.

Bokil H, Andrews P, Kulkarni JE, Mehta S, Mitra PP (2010) Chronux: a platform for analyzing neural signals. J Neurosci Methods 192:146-151.

Bottenstein JE, Sato GH (1979) Growth of a rat neuroblastoma cell line in serum-free supplemented medium. Proc Natl Acad Sci U S A 76:514517. 
Bouet V, Boulouard M, Toutain J, Divoux D, Bernaudin M, Schumann-Bard P, Freret T (2009) The adhesive removal test: a sensitive method to assess sensorimotor deficits in mice. Nat Protoc 4:1560-1564.

Boyden ES, Zhang F, Bamberg E, Nagel G, Deisseroth K (2005) Millisecondtimescale, genetically targeted optical control of neural activity. Nat Neurosci 8:1263-1268.

Carmichael ST, Wei L, Rovainen CM, Woolsey TA (2001) New patterns of intracortical projections after focal cortical stroke. Neurobiol Dis 8:910-922.

Chau MJ, Deveau TC, Song M, Gu X, Chen D, Wei L (2014) iPSC transplantation increases regeneration and functional recovery after ischemic stroke in neonatal rats. Stem Cells 32:3075-3087.

Chen D, Lee J, Gu X, Wei L, Yu SP (2015) Intranasal delivery of Apelin-13 is neuroprotective and promotes angiogenesis after ischemic stroke in mice. ASN Neuro 7:1759091415605114.

Chen Y, Xiong M, Dong Y, Haberman A, Cao J, Liu H, Zhou W, Zhang SC (2016) Chemical control of grafted human PSC-derived neurons in a mouse model of Parkinson's disease. Cell Stem Cell 18:817-826.

Cheng MY, Wang EH, Woodson WJ, Wang S, Sun G, Lee AG, Arac A, Fenno LE, Deisseroth K, Steinberg GK (2014) Optogenetic neuronal stimulation promotes functional recovery after stroke. Proc Natl Acad Sci U S A 111:12913-12918.

Choi KE, Hall CL, Sun JM, Wei L, Mohamad O, Dix TA, Yu SP (2012) A novel stroke therapy of pharmacologically induced hypothermia after focal cerebral ischemia in mice. FASEB J 26:2799-2810.

Cunningham M, Cho JH, Leung A, Savvidis G, Ahn S, Moon M, Lee PK, Han JJ, Azimi N, Kim KS, Bolshakov VY, Chung S (2014) hPSC-derived maturing GABAergic interneurons ameliorate seizures and abnormal behavior in epileptic mice. Cell Stem Cell 15:559-573.

Daadi MM, Klausner JQ, Bajar B, Goshen I, Lee-Messer C, Lee SY, Winge MC, Ramakrishnan C, Lo M, Sun G, Deisseroth K, Steinberg GK (2016) Optogenetic stimulation of neural grafts enhances neurotransmission and downregulates the inflammatory response in experimental stroke model. Cell Transplant 25:1371-1380.

Duan J, Fu H, Zhang J (2017) Activation of parvalbumin-positive neurons in both retina and primary visual cortex improves the feature-selectivity of primary visual cortex neurons. Neurosci Bull 33:255-263.

Fornito A, Zalesky A, Breakspear M (2015) The connectomics of brain disorders. Nat Rev Neurosci 16:159-172.

Freiherr J, Hallschmid M, Frey WH 2nd, Brünner YF, Chapman CD, Hölscher C, Craft S, De Felice FG, Benedict C (2013) Intranasal insulin as a treatment for Alzheimer's disease: a review of basic research and clinical evidence. CNS Drugs 27:505-514.

Hanson LR, Frey WH 2nd (2008) Intranasal delivery bypasses the bloodbrain barrier to target therapeutic agents to the central nervous system and treat neurodegenerative disease. BMC Neurosci 9 [Suppl 3]:S5.

Hicks A, Schallert T, Jolkkonen J (2009) Cell-based therapies and functional outcome in experimental stroke. Cell Stem Cell 5:139-140.

Kato HE, Zhang F, Yizhar O, Ramakrishnan C, Nishizawa T, Hirata K, Ito J, Aita Y, Tsukazaki T, Hayashi S, Hegemann P, Maturana AD, Ishitani R, Deisseroth K, Nureki O (2012) Crystal structure of the channelrhodopsin light-gated cation channel. Nature 482:369-374.

Kelly S, Bliss TM, Shah AK, Sun GH, Ma M, Foo WC, Masel J, Yenari MA, Weissman IL, Uchida N, Palmer T, Steinberg GK (2004) Transplanted human fetal neural stem cells survive, migrate, and differentiate in ischemic rat cerebral cortex. Proc Natl Acad Sci U S A 101:11839-11844.

Kobelt LJ, Wilkinson AE, McCormick AM, Willits RK, Leipzig ND (2014) Short duration electrical stimulation to enhance neurite outgrowth and maturation of adult neural stem progenitor cells. Ann Biomed Engin 42:2164-2176.

Kolarow R, Brigadski T, Lessmann V (2007) Postsynaptic secretion of BDNF and NT-3 from hippocampal neurons depends on calciumcalmodulin kinase II signaling and proceeds via delayed fusion pore opening. J Neurosci 27:10350-10364.

Kurozumi K, Nakamura K, Tamiya T, Kawano Y, Ishii K, Kobune M, Hirai S, Uchida H, Sasaki K, Ito Y, Kato K, Honmou O, Houkin K, Date I, Hamada H (2005) Mesenchymal stem cells that produce neurotrophic factors reduce ischemic damage in the rat middle cerebral artery occlusion model. Mol Ther 11:96-104.

Lee JH, Wei ZZ, Cao W, Won S, Gu X, Winter M, Dix TA, Wei L, Yu SP (2016) Regulation of therapeutic hypothermia on inflammatory cyto- kines, microglia polarization, migration and functional recovery after ischemic stroke in mice. Neurobiol Dis 96:248-260.

Lioutas VA, Alfaro-Martinez F, Bedoya F, Chung CC, Pimentel DA, Novak V (2015) Intranasal insulin and insulin-like growth factor 1 as neuroprotectants in acute ischemic stroke. Transl Stroke Res 6:264-275.

Lonze BE, Ginty DD (2002) Function and regulation of CREB family transcription factors in the nervous system. Neuron 35:605-623.

Lu X, Agasti SS, Vinegoni C, Waterman P, DePinho RA, Weissleder R (2012) Optochemogenetics (OCG) allows more precise control of genetic engineering in mice with CreER regulators. Bioconjug Chem 23:1945-1951.

Mamounas LA, Altar CA, Blue ME, Kaplan DR, Tessarollo L, Lyons WE (2000) BDNF promotes the regenerative sprouting, but not survival, of injured serotonergic axons in the adult rat brain. J Neurosci 20:771-782.

Marques JM, Olsson IA (2010) Performance of juvenile mice in a reach-tograsp task. J Neurosci Methods 193:82-85.

Matsuda N, Lu H, Fukata Y, Noritake J, Gao H, Mukherjee S, Nemoto T, Fukata M, Poo MM (2009) Differential activity-dependent secretion of brain-derived neurotrophic factor from axon and dendrite. J Neurosci 29:14185-14198.

Meredith ME, Salameh TS, Banks WA (2015) Intranasal delivery of proteins and peptides in the treatment of neurodegenerative diseases. AAPS J 17:780-787.

Mohamad O, Drury-Stewart D, Song M, Faulkner B, Chen D, Yu SP, Wei L (2013) Vector-free and transgene-free human iPS cells differentiate into functional neurons and enhance functional recovery after ischemic stroke in mice. PLoS One 8:e64160.

Murphy TH, Corbett D (2009) Plasticity during stroke recovery: from synapse to behaviour. Nat Rev Neurosci 10:861-872.

Novak V, Milberg W, Hao Y, Munshi M, Novak P, Galica A, Manor B, Roberson P, Craft S, Abduljalil A (2014) Enhancement of vasoreactivity and cognition by intranasal insulin in type 2 diabetes. Diabetes Care 37:751759.

Page P (2014) Beyond statistical significance: clinical interpretation of rehabilitation research literature. Int J Sports Phys Ther 9:726-736.

Palay SL (1956) Synapses in the central nervous system. J Biophys Biochem Cytol 2:193-202

Pandian S, Arya KN, Kumar D (2016) Minimal clinically important difference of the lower-extremity Fugl-Meyer Assessment in chronic-stroke. Top Stroke Rehabil 23:233-239.

Park H, Poo MM (2013) Neurotrophin regulation of neural circuit development and function. Nat Rev Neurosci 14:7-23.

Paz JT, Davidson TJ, Frechette ES, Delord B, Parada I, Peng K, Deisseroth K, Huguenard JR (2013) Closed-loop optogenetic control of thalamus as a tool for interrupting seizures after cortical injury. Nat Neurosci 16:64-70.

Petersen CC (2007) The functional organization of the barrel cortex. Neuron 56:339-355.

Quiroga RQ, Nadasdy Z, Ben-Shaul Y (2004) Unsupervised spike detection and sorting with wavelets and superparamagnetic clustering. Neural Comput 16:1661-1687.

Rolston JD, Gross RE, Potter SM (2009) A low-cost multielectrode system for data acquisition enabling real-time closed-loop processing with rapid recovery from stimulation artifacts. Front Neuroeng 2:12.

Simons DJ, Woolsey TA (1979) Functional organization in mouse barrel cortex. Brain Res 165:327-332.

Spetter MS, Hallschmid M (2015) Intranasal neuropeptide administration to target the human brain in health and disease. Mol Pharm 12:27672780.

Steinbeck JA, Jaiswal MK, Calder EL, Kishinevsky S, Weishaupt A, Toyka KV, Goldstein PA, Studer L (2016) Functional connectivity under optogenetic control allows modeling of human neuromuscular disease. Cell Stem Cell 18:134-143.

Tayebati SK, Nwankwo IE, Amenta F (2013) Intranasal drug delivery to the central nervous system: present status and future outlook. Curr Pharm Des 19:510-526.

Temereanca S, Simons DJ (2003) Local field potentials and the encoding of whisker deflections by population firing synchrony in thalamic barreloids. J Neurophysiol 89:2137-2145.

Theus MH, Wei L, Cui L, Francis K, Hu X, Keogh C, Yu SP (2008) In vitro hypoxic preconditioning of embryonic stem cells as a strategy of promoting cell survival and functional benefits after transplantation into the ischemic rat brain. Exp Neurol 210:656-670. 
Trounson A, McDonald C (2015) Stem cell therapies in clinical trials: progress and challenges. Cell Stem Cell 17:11-22.

Tung JK, Gutekunst CA, Gross RE (2015) Inhibitory luminopsins: genetically-encoded bioluminescent opsins for versatile, scalable, and hardware-independent optogenetic inhibition. Sci Rep 5:14366.

van Velthoven CT, Sheldon RA, Kavelaars A, Derugin N, Vexler ZS, Willemen HL, Maas M, Heijnen CJ, Ferriero DM (2013) Mesenchymal stem cell transplantation attenuates brain injury after neonatal stroke. Stroke 44:1426-1432.

Wan L, Xia R, Ding W (2010) Low-frequency electrical stimulation improves neurite outgrowth of dorsal root ganglion neurons in vitro via upregulating $\mathrm{Ca}^{2+}$-mediated brain-derived neurotrophic factor expression. Neural Regen Res 5:1256-1260.

Wei L, Rovainen CM, Woolsey TA (1995) Ministrokes in rat barrel cortex. Stroke 26:1459-1462.

Wei L, Ying DJ, Cui L, Langsdorf J, Yu SP (2004) Necrosis, apoptosis and hybrid death in the cortex and thalamus after barrel cortex ischemia in rats. Brain Res 1022:54-61.

Wei L, Cui L, Snider BJ, Rivkin M, Yu SS, Lee CS, Adams LD, Gottlieb DI, Johnson EM Jr, Yu SP, Choi DW (2005) Transplantation of embryonic stem cells overexpressing bcl-2 promotes functional recovery after transient cerebral ischemia. Neurobiol Dis 19:183-193.
Wei N, Yu SP, Gu X, Taylor TM, Song D, Liu XF, Wei L (2013) Delayed intranasal delivery of hypoxic-preconditioned bone marrow mesenchymal stem cells enhanced cell homing and therapeutic benefits after ischemic stroke in mice. Cell Transplant 22:977-991.

Wei ZZ, Gu X, Ferdinand A, Lee JH, Ji X, Ji XM, Yu SP, Wei L (2015) Intranasal delivery of bone marrow mesenchymal stem cells improved neurovascular regeneration and rescued neuropsychiatric deficits after neonatal stroke in rats. Cell Transplant 24:391-402.

Yi H, Leunissen J, Shi G, Gutekunst C, Hersch S (2001) A novel procedure for pre-embedding double immunogold-silver labeling at the ultrastructural level. J Histochem Cytochem 49:279-284.

Yona G, Meitav N, Kahn I, Shoham S (2016) Realistic numerical and analytical modeling of light scattering in brain tissue for optogenetic applications. eNeuro 3:ENEURO.0059-15.2015.

Yu SP, Wei Z, Wei L (2013) Preconditioning strategy in stem cell transplantation therapy. Transl Stroke Res 4:76-88.

Zhang LI, Poo MM (2001) Electrical activity and development of neural circuits. Nat Neurosci 4 [Suppl]:1207-1214.

Zhang L, Schallert T, Zhang ZG, Jiang Q, Arniego P, Li Q, Lu M, Chopp M (2002) A test for detecting long-term sensorimotor dysfunction in the mouse after focal cerebral ischemia. J Neurosci Methods 117:207-214. 